\section{Por uma epidemiologia da saúde coletiva}

\section{For an epidemiology of the collective health}

São antigas as observações críticas de autores latino-americanos com relação à denominada epidemiologia moderna. Porém, mais recentemente e em frequência crescente, críticas similares têm aparecido na literatura internacional. Estas críticas diferenciam-se pelos diagnósticos que apresentam e, como consequência, geram alternativas diferenciadas de encaminhamentos. Enquanto alguns destacam as questões teóricas, outros destacam as questões empíricas. Em seu conjunto, no entanto, expõem as insuficiências da epidemiologia de resolver problemas relacionadas à saúde das populações que, contemporaneamente, lhes são postas. O objetivo deste ensaio foi de, em um primeiro momento, apresentar e sistematizar as críticas à epidemiologia moderna para, em seguida, delinear um conjunto de proposições que contribuam para a discussão sobre o papel da epidemiologia na constituição do campo da saúde coletiva. Agruparam-se em cinco categorias as formas em que se interpreta a crise da epidemiologia: uma crise do seu paradigma dominante; uma crise na sua capacidade de formulação teórica; uma crise resultante da rutura dos seus compromissos históricos; uma crise da relação com a prática da saúde pública; e, uma crise da capacidade explicativa, em consequência do conflito de resultados gerados por diferentes estudos sobre um mesmo tópico. Estas críticas têm estimulado a produção de conhecimentos epidemiológicos alternativos importantes, mesmo que, em muitos momentos, isto aconteça fora do núcleo central da disciplina. Estas alternativas são organizadas em torno de três eixos: $a$ ) as desigualdades em saúde; $b$ ) o ambiente, a qualidade de vida, os conceitos e as medidas de saúde; c) a avaliação e a escolha das tecnologias e intervenções em saúde. Entende-se que em torno destes três eixos pode-se: $a$ ) recuperar muitas das experiências relevantes acumuladas na história da epidemiologia e de outras disciplinas populacionais que vêm contribuindo para o conhecimento da saú- 
de e dos seus determinantes; $b$ ) redirecionar o desenvolvimento teórico, metodológico e operacional da disciplina; $c$ ) deslocar o atual modus operandi da prática científica da epidemiologia para centrá-lo em torno das questões da prevenção e para o desenvolvimento de novas bases éticas, em consonância com os seus compromissos sociais e políticos.

Palavras-chave: Epidemiologia, classificação. Saúde Pública. Fatores socioeconômicos. Condições sociais.

\section{Abstract}

Criticism regarding the so-called modern epidemiology has been present in the Latin-American epidemiological literature for quite some time. More recently, however, similar criticism has increasingly been present in the international literature. These criticisms differ in their diagnosis and, as a consequence, in the alternatives proposed. While some stress the theoretical aspects, others stress the empirical ones. As a whole, however, authors state the inadequacies of epidemiology in solving the health problems of populations that currently challenge it. The aim of this essay was first to present these criticisms in a systematic way, and second to delineate a group of propositions that could contribute to the discussion of the role of epidemiology in forming the field of collective health. The criticisms were organized in five categories according to their views on the epidemiology crisis: a crisis of its dominant paradigm; a crisis in its ability of theoretical formulation; a crisis resulting from the rupture of its historical commitments; a crisis in its relationship with the public health practice; and, a crisis in its explanatory skills, as a consequence of the conflict of results generated by studies in similar topics. It is understandable that such criticisms have stimulated the development of alternative and useful epidemiological knowledge; even so, very often, this happens out of the central core of epidemiology. The possible alternatives are organized around three axes:1) the inequalities in health; 2) the environment, the quality of life, and the concepts and the measurements of health; 3) the evaluation and choice of health technologies and interventions. From these axes it is possible: a) to recover many of the important experiences accumulated in the history of epidemiology and many other subjects that focus on the different aspects of health and its determinants; b) to redirect the theoretical, methodological, and operational development of epidemiology; c) to move the current modus operandi of the scientific practice of epidemiology, to orient it towards prevention and the development of new ethical bases, in consonance with its social and political commitment.

Keywords: Epidemiology, classification. Public Health. Socioeconomic factors. Social conditions.

\section{Introdução}

A epidemiologia tem uma posição peculiar e ainda pouco explorada pelos epistemológos, de conciliar o papel de disciplina científica, portanto produtora de conhecimentos originais sobre o processo saúde e doença e, ao mesmo tempo, de campo profissional, participante dos esforços pelo cuidado da saúde das populações. Esta dupla inserção é o que define algumas das características peculiares da epidemiologia e de onde advém a sua diversidade e as possibilidades de ser pensada e repensada em tantos diferentes ângulos e perspectivas. Esta dupla inserção é reafirmada em algumas das definições clássicas da disciplina, como aquela referida por Last ${ }^{1}$ (1988) - "o estudo da distribuição e determinantes de estados e eventos relacionados à saúde em populações definidas, e a aplicação deste conhecimento para a resolução dos problemas de saúde". As considerações que aqui serão desenvolvidas partem do pressuposto de que existem indivíduos com uma base biológica e genética complexa, que habitam espaços geográficos socialmente organizados, em cujo in- 
terior [os indivíduos] agrupam-se em populações. Estas, ao se deslocarem no tempo, constroem uma história, base para algo maior e mais fundamental, que é o de desenhar as trajetórias por onde pecorrerão o seu futuro. Nesta profunda e complexa dialética multidimensional entre a biologia, o espaço e o tempo é que os indivíduos se definem e, em seu conjunto, definem algo mais complexo do que a mera soma destes - as sociedades. Os eventos mórbidos não são meros acidentes, mas intercorrências que, enquanto possam ser percebidas no nível individual (seja no plano biológico, seja no plano psíquico), têm sua con-figuração populacional definida na confluência destas três dimensões, e como consequência resultante da forma de organização das sociedades.

Este artigo não tem o objetivo de introduzir-se nos grandes desafios epistemológicos que hoje estão postos para a epidemiologia, porém o de tentar, através da análise e da discussão de alguns dos dilemas que esta disciplina atravessa, esboçar algumas proposições para a comunidade de epidemiologistas que atuam, seja no âmbito acadêmico, seja nos serviços de saúde ou correlatos e que compartilham da idéia do caráter imprescindível da epidemiologia na compreensão dos eventos de saúde nas populações humanas e, como consequência, na constituição do campo da saúde coletiva. Busca-se reorganizar um conjunto de questões fundamentais no esforço de contribuir para as reflexões e possíveis reorientações na pesquisa, nas aplicações para a prevenção e, de não menos importância, no compromisso social dos epidemiologistas para com a saúde da sociedade.

Faz-se necessário estabelecer um ponto de equilíbrio entre os desejos, possibilidades e competências de intervenção no mundo real e os limites que estão definidos, tanto pelos conhecimentos científicos e tecnológicos disponíveis ou que se podem produzir, como pelo conjunto de forças sociais e políticas que se conformam na conjuntura em que atuamos. Partindose desta premissa, são apresentadas a seguir, em forma concisa, as questões e dile- mas que, em última instância, estão na base destas reflexões :

1- Questões relacionadas às insu-ficiências do conhecimento epidemiológico disponível, no sentido de suas contribuições para definir o conjunto de intervenções e mudanças que se fazem necessárias com relação a melhorias na situação de saúde. Ao ser definida como a disciplina básica da saúde pública, a epidemiologia passa a ter como responsabilidade gerar conhecimentos, informações e tecnologias que embasem as políticas de prevenção e controle das doenças e outros eventos na saúde.

2- Questões geradas pelo reconhecimento da necessidade da epidemiologia continuar contribuindo, de forma mais completa, para o entendimento das causas, determinantes e raízes históricas e sociais das doenças e outros eventos na saúde, bem como dos efeitos gerados em consequência dos esforços desenvolvidos para a sua prevenção e controle. Isto permitiria uma maior interferência das sociedades sobre os fatores que modificam o curso histórico desses eventos e, em última instância, ampliaria a capacidade de prever e modificar as suas tendências.

3 - Questões relacionadas à necessidade de ampliar-se a compreensão dos eventos mórbidos para além das suas dimensões biológicas, reforçando o desenvolvimento de medidas que registrem não somente os níveis das doenças, mas também outras dimensões do sofrimento humano, contribuindo para que consolidemos a idéia de saúde como parte do complexo da qualidade de vida e do bem estar social, e não simplesmente como a ausência ou a presença da doença.

4 - Questões relacionadas a sua ainda limitada influência nos sistemas de decisão sobre o uso indiscriminado e, muitas vezes iatrogênico, de uma série de tecnologias inúteis (ao lado, evidentemente, de outras tantas úteis) que muito pouco têm contribuído para mudar a situação de saúde das sociedades e que mais atuam como "tótens" modernos, produtores de ilusões, que desperdiçam recursos e expectativas das sociedades e dos indivíduos. 
5 - Dilemas do pesquisador que busca caminhos por onde seja possível a produção de conhecimentos que reflitam as preocupações apresentadas nos 4 itens listados acima, e que acredita que, relativamente a diversos temas cruciais, por razões muitas vezes alheias à sua vontade, em lugar de buscar respostas, mesmo que incompletas, para as questões corretas, em muitos momentos faz um enorme esforço, certamente sincero, de dar respostas certíssimas para questões irrelevantes.

6 - Dilemas do professor que busca passar para seus alunos não somente conhecimentos coerentes e instrumentos que os capacitem técnica e cientificamente para o cumprimento das suas obrigações profissionais, mas também inquietações pois, ao lidar com uma questão tão sensível como a saúde das sociedades, obrigatoriamente se situa na confluência entre o ser profissional e o ser político.

\section{A epidemiologia moderna e suas crises}

São antigas as observações críticas de autores latino-americanos sobre a epidemiologia na sua forma contemporânea, por alguns denominada de epidemiologia moderna (Rothman, ${ }^{2}$ 1986). Estas críticas enfatizam as insuficiências no que concerne à produção de conhecimentos coerentes com o propósito de compreender e explicar a ocorrência das doenças e de outros agravos à saúde das populações, como consequência, reduzindo-se as suas possibilidades de contribuir para a prevenção e o controle destes eventos (Almeida-Filho, ${ }^{3}$ 1992; Barata e Barreto ${ }^{4}$, 1997; Breilh, ${ }^{5}$ 1997). Porém, o mais interessante é que críticas similares se fazem crescentes na literatura epide-miológica internacional, principalmente na de origem norte-americana. Em anos recentes, uma série de artigos de autores influentes, publicados em revistas científicas de saúde publica e, particularmente, da epidemiologia, têm levantado questões e críticas importantes (Long' 1993; Krieger ${ }^{7}, 1994 ; \mathrm{McMichael}^{8}, 1995$; Pearce $^{9}$, 1996; Susser e Susser ${ }^{10}$, 1996; Sus- ser e Susser ${ }^{11}$, 1996; Shy ${ }^{12}$, 1997). Apesar de muitas destas críticas terem conteúdo similar àquelas já feitas por autores latinoamericanos, no novo contexto ganham especial ressonância.

É importante precisar o que entendemos pelo núcleo de idéias que conformam a epidemiologia moderna. Tendo por epicentro o ambiente acadêmico norte-americano, esta corrente consolidou-se em décadas recentes, tornando-se a tendência dominante na produção científica internacional na epidemiologia (Susser ${ }^{13}, 1985$; Barreto $^{14}, 1990$ ). No esforço de diferenciála das "outras epidemiologias" é essencial compreender como, no seu interior, constroem-se os problemas científicos. Na sua vertente mais radical, seria problema epidemiológico aquele que, embora relativo à ocorrência de eventos mórbidos em populações, tenha a sua observação e sua análise realizadas no nível individual. As implicações desta abordagem são surpreendentes. Assim, Miettinem ${ }^{15}$ (1985), em seu importante livro que sintetiza as formulações fundamentais desta vertente da epidemiologia, chega a afirmar que "a ocorrência de epidemias, a preocupação central da epidemiologia clássica, não é um problema da forma característica da pesquisa epidemiológica moderna" (p. 4-5) e, ainda, que "o paradigma para a epidemiologia moderna não é o estudo da ocorrência da doença em sua forma epidêmica, mas sim da forma endêmica" (p. 5). Assim, ao retirar a noção de população como a fonte geradora dos problemas epidemiológicos, também o retira como central na formulação das propostas de prevenção. Despreza as definições mais clássicas da disciplina e, conforme observou Rose ${ }^{16}$ (1992), desloca o interesse para "os determinantes dos casos, não os determinantes da incidência”. Não é por acaso o fato de que a denominada epidemiologia clínica, centrada no estudo de casos, derivou-se do seu interior.

Após um vertiginoso desenvolvimento nas décadas de 1970 e 1980, a epidemiologia moderna começa a apresentar sinais de esgotamento, reduzindo sua capacidade de apresentar contribuições mais significati- 
vas no sentido de entender e solucionar os complexos problemas sanitários, mesmo das sociedades desenvolvidas. Críticas começam a emergir nos próprios núcleos acadêmicos onde esta vertente da epidemiologia teve sua origem. Neste contexto, o que inicialmente era apenas a identificação de problemas e insuficiências, paulatinamente evoluiu para críticas mais contundentes, que explicitam a necessidade de mudanças mais profundas no curso da disciplina. Apesar de apresentarem pontos em comum, estas críticas vêm de diferentes contextos e são fundadas em diferentes motivações e percepções sobre o papel da epidemiologia. Evidentemente, também apresentam diferenças no que diz respeito às soluções que propõem ou às tendências que antevêem. Como este debate, ainda parcialmente codificado, tende a confundir os menos iniciados na disciplina, apresenta-se a seguir um sistematização das diversas maneiras como, na literatura científica, tem sido apresentada a crise ou as crises da epidemiologia moderna.

a) Uma crise do seu paradigma dominante - Susser e Susser ${ }^{10}$ (1996) periodizam a evolução da epidemiologia em três eras sucessivas, cada uma das quais tendo o seu paradigma dominante. Em cada era estrutura-se também uma abordagem preventiva, que se torna hegemônica. A primeira, a era das estatísticas sanitárias, teve como paradigma dominante o miasma, sendo seguida pela era das doenças infecciosas, com a teoria dos germes, e por fim a era atual, quando predominam as doenças crônicas, com o paradigma da "caixa preta". No entendimento destes autores, este último paradigma será necessariamente superada por um novo, o qual se caracterizaria por responder aos novos desafios postos para a epidemiologia e pela integração das várias dimensões da realidade que os conhecimentos recentes têm desvendado.

b) Uma crise de formulações teóricas entende-se que falta à epidemiologia estabelecer novos fundamentos teóricos que venham permitir avanços em sua prática de investigação. Apesar da pequena importância conferida às questões teóricas ao interior da epidemiologia moderna, elas têm sido sempre fundamentais para guiar o trabalho dos epidemiologistas. Krieger e Zierler $^{17}$ (1996) observam que a epidemiologia diferencia-se de outras disciplinas populacionais pela sua base teórica e não pelos seus métodos e técnicas. Avançando na questão, distinguem três componentes das teorias epidemiológicas: as teorias epidemiológicas propriamente ditas, que buscam explicar a saúde na população; as teorias causais, que formam a base para os modelos de causalidade das doenças; e as teorias do erro, que guiam o desenho, análise e interpretação dos estudos epidemiológicos. A aplicação dos dois últimos componentes gera o núcleo metodológico da disciplina, enquanto o primeiro organiza as bases filosóficas e ideológicas da nossa compreensão da saúde das populações.

c) Uma crise resultante da ruptura dos compromissos históricos da epidemiologia - a epidemiologia moderna é acusada de não exercer a contento seu papel de disciplina básica da saúde pública, tendo direcionado os seus esforços para o estudo das dimensões individuais e clínicas da saúde. A epidemiologia não estaria cumprindo sua missão de desenvolver o método científico necessário para construir os conhecimentos que devem fundamentar a missão básica da saúde pública de prevenção das doenças e promoção da saúde das populações $\left(\right.$ Shy ${ }^{12}$, 1997). O ponto fundamental desta mudança é identificado na transferência do nível de análise da população para o indivíduo. Wing ${ }^{18}$ (1994) observa que o conceito de população desapareceu de algumas definições da epidemiologia, que passa a centrar seus objetivos nas relações de ocorrência das doenças. A população passa a ser, apenas, uma série de indivíduos enumerados, com o objetivo de dar poder e significância aos testes estatísticos. Contraditoriamente, o conceito de risco que emerge, embora não possa ser medido no nível individual, passa, conceitualmente, a ser uma propriedade dos indivíduos. O método científico de referência passa a ser o ensaio clínico. Fundamentase no individualismo, pois tem nítida ten- 
dência à responsabilização do indivíduo pela ocorrência dos eventos mórbidos e pela prevenção dos fatores de risco. Os fatores sociais e econômicos passam a ser minimizados e as relações entre a saúde e a política tendem a ser desprezadas. Há aqui a idéia de que a "epidemiologia tradicional", mesmo que carente dos recursos analíticos disponíveis na atualidade, foi capaz de formular idéias e acumular evidências sobre as causas da ocorrência das doenças, as quais resultaram em políticas de prevenção eficientes e radicais (Pearce ${ }^{9}$, 1996).

d) Uma crise da sua relação com a prática da saúde publica - em uma perspectiva mais pragmática que a anterior, identifica-se a inadequação de grande parte do conhecimento produzido sobre a saúde das populações, assim como as proposições relativas à prevenção derivadas deste conhecimento. Apesar de reconhecer o papel primordial da epidemiologia na pesquisa sobre a saúde da população, entende que o desenvolvimento do conhecimento realmente necessário para fundamentar as práticas de promoção à saúde e para a condução das mudanças necessárias na organização dos serviços de saúde necessita de abordagens multidisciplinares (Dean e Hunter ${ }^{19}$, 1996). Os modelos quantitativos de risco têm explicado apenas parte dos determinantes dos problemas de saúde que afligem as populações. Fatores que não são nem podem vir a ser detectados por esta estratégia de investigação, muitas vezes respondem por uma parte substancial do risco. Em consequência, grandes frustrações podem ocorrer com relação à efetividade de medidas preventivas derivadas de estimativas de riscos, que apenas explicam uma parte menor do processo causal (Evans e Stoddart ${ }^{20}, 1994$ ).

e) Uma crise da capacidade explicativa - de cunho empirista e utilitarista, que identifica o problema na frequente discordância entre os valores das medidas de risco de um mesmo fator, em diferentes estudos (Angell21 ${ }^{21}$ 1990; Taubes $^{22}$, 1995). Nos pressupostos clássicos da epidemiologia, para a aceitação de um fator como causal, está a idéia da força da associação medida pela magnitude do risco relativo. Alto grau de concordância, entre os resultados de estudos que envolvam a análise de fatores associados a seus respectivos efeitos através de altos riscos relativos, é esperado e com frequência ocorre. Entretanto, como a maioria dos fatores de risco são vinculados aos seus respectivos efeitos através de riscos relativos baixos, a discordância entre estudos é frequente. São clássicos, na literatura epidemiológica, os exemplos do cigarro ou de algumas radiações ionizantes que se associam aos seus efeitos por altos riscos relativos. Resultados que são consistentemente reproduzidos em estudos realizados em diferentes locais e em diferentes épocas. Em muitos outros casos a controvérsia é o mais comum, produzindo-se resultados falsos negativos ou falsos positivos. Como conseqüência, geram-se dúvidas e ansiedades, como por exemplo, entre profissionais e leigos ao avaliarem a importância ou não de um dado fator de risco e a consequente necessidade de esforços para o seu controle (Taubes ${ }^{22}, 1995$ ) ou, entre técnicos e legisladores, quando da normatização de padrões de exposição ambiental (McMichael23 ${ }^{23}$, 1989).

\section{Algumas proposições}

Ao lado do reconhecimento da importância que a discussão dos impasses da epidemiologia tem para o seu desenvolvimento como disciplina científica, devemos também chamar a atenção para um conjunto de esforços paralelos que buscam a superação de questões conceituais ou o desenvolvimento de novas abordagens metodológicas com vistas à produção de novos conhecimentos. Muitas destas atividades estão sendo praticadas em outras disciplinas, nem sempre próximas à saúde pública, gerando, entretanto, subprodutos que podem ser aplicados aos estudos sobre as condições de saúde e os seus determinantes. Em toda fase transicional da produção dos conhecimentos ou das práticas, como tem acontecido em diferentes momentos na história da epidemiologia e 
da saúde pública, são processos de desenvolvimento de conhecimentos e experiências, em permanente sintonia com as necessidades presentes e futuras das sociedades que, em seu conjunto, estimulam a construção de inovações teóricas, metodológicas ou operacionais. Neste sentido, é importante ressaltar os esforços feitos por alguns que, em consonância com o contexto, as indefinições e as necessidades atuais, muitas vezes marchando fora do núcleo central de epidemiologia moderna, contribuem para a construção, seja de novos conhecimentos, seja de novas estratégias que transformem os conhecimentos disponíveis em ações positivas de saúde. Tais movimentos são prenúncios de tendências que despontam ou sinalizam o renascimento de tradições epidemiológicas que foram secundarizadas no passado recente. No sentido de organizar estes esforços, os mesmos foram agrupados em torno de três eixos básicos: desigualdades em saúde; ambiente, qualidade de vida e medições da saúde; e avaliação e escolha das intervenções em saúde. Em conjunto, estes eixos cobrem grande parte, se não a totalidade, das questões colocadas para uma epide-miologia da saúde coletiva.

\section{Desigualdades em saúde}

Enquanto se identifica a necessidade do desenvolvimento teórico da epidemiologia, deve-se chamar a atenção para o fato de que a sua estratégia fundamental de produção de conhecimentos continuará tendo por base os estudos empíricos. Essa vocação para a análise empírica, se de um lado tem levado a epidemiologia a relativizar os debates sobre as questões teóricas, por outro lado tem trazido muitas contribuições inovadoras, inclusive no que diz respeito às novas formas de mensuração dos fenômenos que aborda. Especificamente no que concerne à mensuração das variáveis sociais e ambientais, existe uma rica experiência acumulada. Não é por acaso que discussões sobre a questão das classes sociais e de outras variáveis sociais, em suas diversas abordagens teóricas, têm perpassado tão intensamente a epidemiologia. Por exemplo, vale a pena notar que, entre as poucas tentativas de transformar o conceito marxista de classe social em algo mensurável, algumas foram feitas como parte de estudos epide-miológicos (Solla $\left.{ }^{24}, 1996\right)$. Isto significa que, a partir de referências teóricas, no caso da sociologia marxista, desenvolveu-se um sistema de medidas supostamente capaz de ser operado empiricamente $\mathrm{e}$, mais do que isto, quantitativamente, que classifica cada indivíduo de uma população em sua classe social.

A questão da desigualdade na distribuição da doença tem sido tratada mais enfaticamente com relação à dimensão socioeconômica. Uma vasta literatura tem sido desenvolvida sobre a utilização de indicadores proxy de grupos ou classes sociais. Muitos destes estudos, apesar da clara descontextualização (ou desteorização) das categorias sociais e econômicas que utilizam, em seu conjunto, constituem-se em um imenso patrimônio para o conhecimento das desigualdades sociais em saúde (Liberatos e col..$^{25}$, 1988). Porém, na atualidade, o entendimento das desigualdades tem se tornado mais complexo, tanto no que diz respeito às formas empíricas de observá-las, como também em relação à forma como os diversos grupos, estratos e classes sociais posicionam-se na relação uns com os outros. Novas compreensões do fenômeno das desigualdades são geradas, tanto a partir de percepções acadêmicas, como a partir de reflexões e ações no interior dos próprios grupos sociais. Estes, ao se organizarem como movimentos sociais ou culturais em busca de identidade e caráter próprios, elaboram sobre as diferenças e as desigualdades com relação aos grupos hegemônicos da sociedade. Assim, além das classes sociais, definidas de diferentes maneiras em acordo com as diferentes teorias sociais, desigualdades são identificadas com relação ao gênero, à raça, aos grupos religiosos ou culturais etc. (Cochrane e col. ${ }^{26}$, 1982; Krieger e Fee ${ }^{27}$, 1994). Mesmo que tenham a sua usina geradora na estrutura produtiva da sociedade, as desigualdades espraiam-se e assumem dife- 
rentes configurações nos mais diversos planos da organização social e nos diversos momentos históricos de cada sociedade. Há razoáveis evidências empíricas de que as condições de saúde observáveis nas populações acompanham a forma com que estas desigualdades se apresentam (Wilkinson $^{28}$, 1996).

Além das particularidades que assumem as desigualdades nas condições de saúde é, também, importante entender os enfoques fundamentais que têm guiado o entendimento dessas desigualdades. Revendo os debates desta questão, desde o século XIX até o presente, podemos identificar dois paradigmas fundamentais. $\mathrm{O}$ primeiro, que tem sido o mais influente mesmo em tempos atuais, foi desenvolvido no século XIX e fundamenta-se nas observações de que, em sociedades desiguais, determinados grupos populacionais não atingem patamares mínimos que lhes permitam acesso a bens e serviços fundamentais, o que gera deprivações tanto de bens materiais(saneamento, alimentação etc.) como de bens cultu-rais(educação, informação etc.). Este paradigma, principalmente no que se refere a deprivações de bens materiais, tem servido para o entendimento das desigualdades observadas na ocorrência das doenças infecciosas e das deficiências nutricionais (Engels ${ }^{29}, 1977$; Taylor e Rieger ${ }^{30}$, 1984). Diferenças notadas no plano cultural, ou seja, em elementos despojados de materialidade, têm sido utilizadas para explicar desigualdades observadas na ocorrência das doenças cardiovasculares, dos cânceres, da violência, da obesidade, da exposição a agentes químicos etc., já que carências materiais, conquanto se apresentem associadas a esses problemas, nem sempre satisfazem outros pressupostos de causalidade epidemiológica. No decorrer da primeira metade do presente século, foi verificado, nos atuais países desenvolvidos, o aumento crescente de muitas doenças crônicas, mesmo em períodos em que políticas sociais permitiram reduzir a pobreza absoluta. Assim, tornava-se necessário um novo paradigma que explicasse este aumento na ocorrên- cia destas doenças e as desigualdades que, em paralelo, eram observadas. As primeiras elaborações encontram-se em torno da epidemiologia social, desenvolvida por Cassel $^{31,32}$ (1964; 1976) que, utilizando-se da teoria do stress, elabora o conceito de fatores stressores gerados por processos adaptativos sociais que determinariam o perfil de saúde de uma população. Não seria mais a carência absoluta, mas sim a forma de inserção e de relação do indivíduo em seu meio social que desencadearia a doença. Este núcleo de idéias tem evoluído no sentido de hoje se entender que a desigualdade, mesmo não gerando deficiências absolutas é, em si só, um fator gerador de doenças. Há evidências de que entre sociedades com níveis econômicos similares, aquelas mais igualitárias no que concerne à distribuição de suas riquezas tendem a apresentar mais altos níveis de saúde (Wilkin$\left.\operatorname{son}^{28,33}, 1996,1997\right)$.

Entre as consequências do conhecimento sobre as desigualdades no risco de adoecer, estão os impasses que emergem nos momentos em que se busca transformar estes conhecimentos em ações voltadas à promoção e à prevenção em saúde. As experiências acumuladas no curso da história mostram que esta não é uma tarefa fácil e, com frequência, servem para definir os limites da saúde coletiva e da epidemiologia enquanto campos profissionais. Entretanto, alguns desenvolvimentos são exemplares e mostram as potencialidades da investigação epidemiológica fundada no marco das desigualdades. As desigualdades existentes, mas nem sempre observáveis no nível dos indivíduos, transferemse para a dimensão espacial, sendo detectáveis quando se comparam países, regiões, cidades, ou mesmo zonas de uma mesma cidade. Não é por menos que as relações entre os padrões espaciais e os fenômenos de saúde constituem-se em um significativo exemplo da importância do desenvolvimento do conhecimento das desigualdades em saúde. A demonstração da existência de extremas desigualdades espaciais nos níveis de saúde, a vinculação deste fenômeno com os padrões das desigualda- 
des sociais (Stephens $\left.{ }^{34}, 1996\right)$ e a disponibilidade de informações sobre unidades espaciais nos sistemas rotineiros de informações de muitos países têm estimulado esforços para: a) construção de categorizações espaciais dos eventos de saúde que sejam proxys das categorizações sociais (Paim $\left.{ }^{35}, 1997\right)$; b) desenvolvimento de novas técnicas analíticas, que permitam o manejo mais eficiente dessas informações e a produção de novos conhecimentos (Akerman $^{36}$, 1997; Borell ${ }^{37}$, 1997; Scwarcwald e Leal ${ }^{38}$, 1997); c) desenvolvimento de estratégias que aumentem a precisão no que diz respeito às prioridades para a prevenção e promoção da saúde, bem como para as políticas sociais em geral (Stephens $^{34}$, 1996). Como seria de esperar, desafios conceituais, metodológicos e técnicooperacionais permanecem e necessitam ser superados. Entre estes, pode-se citar a tão propalada "falácia ecológica" relacionada a conhecimentos gerados sobre dados agregados (Schwartz ${ }^{39}$, 1994; Barreto e $\mathrm{Carmo}^{40}$, 1995). No terreno da aplicação, Slogett e Joshi ${ }^{41}$ (1994) observam, na Inglaterra, onde existe uma longa tradição do uso de pequenos setores espaciais como unidades na investigação epidemiológica e na definição de prioridades em saúde que, políticas fundadas apenas em conhecimentos gerados a partir de agregados espaciais, mesmo quando operacionalmente convenientes, podem conter graus importantes de iniqüidades.

As desigualdades em saúde têm sido apresentadas sob duas diferentes formas $\left(\right.$ Vagero $\left.^{42}, 1995\right)$. A primeira, relativa à chance de ficar doente, que reflete a distribuição desigual dos determinantes sociais, culturais e ambientais das doenças, e a segunda, em estando doente, relativa ao acesso ao cuidado que, em uma sociedade de mercado, reflete a capacidade de consumo dos diferentes grupos desta sociedade. Contemporaneamente, muitas sociedades, incluindo o Brasil, adotam entre os seus direitos sociais (nem sempre respeitados) o acesso igualitário do indivíduo doente aos serviços de saúde. Isto significa que a sociedade deveria, por princípio, assumir a responsabi- lidade pela cura de qualquer indivíduo doente, independente da sua origem no sistema social. No tocante à proteção relacionada com a chance de ficar doente, ou seja à prevenção, existe um menor grau de consenso sobre sua constituição como um direito social. Portanto, se há um crescente grau de consenso de que as desigualdades no acesso aos serviços de saúde sejam percebidas como iniquidades, o mesmo não acontece com relação ao risco de adoecer, a despeito de que a Constituição Brasileira, de uma forma bastante avançada neste aspecto, assegure no seu artigo 196 proteção aos riscos para todos os cidadãos do país.

Avanços no conhecimento, ainda que necessários, não têm sido suficientes para provocar reduções nas desigualdades relativas ao risco de adoecer. É próprio das utopias propor a extinção pura e simples de tais desigualdades. Porém, no mundo real, faz-se necessário transformações e intervenções complexas em esferas que, em geral, estão fora da capacidade de intervenção dos epidemiologistas ou de outros profissionais da saúde coletiva. Neste contexto, cabe à epidemiologia, através do seu patrimônio conceitual e metodológico, desnudar as desigualdades em saúde, transformando o conhecimento produzido em fundamentos para estratégias que possam reduzí-las (Goldbaum ${ }^{43}, 1997$ ). Em decorrência do seu compromisso com mudanças efetivas nos níveis de saúde da população, cabe a tarefa não menos importante de, em forma convincente, informar aos diversos agentes sociais sobre as implicações humanas, morais e éticas consequentes à manutenção de tais desigualdades. Não há dúvida de que uma posição com relação a este dilema é central para, de um lado, evitar a transformação da epidemiologia em uma disciplina em busca apenas de soluções tecnicistas e naturalistas para os seus achados e, do outro lado, retirar a justificativa para a sua existência como disciplina autônoma, pela perda da especificidade do seu objeto quando se dilui com outras disciplinas que estudam o social. 


\section{Ambiente, qualidade de vida, conceitos e medidas da saúde}

Em suas origens, o conhecimento epidemiológico, ainda sob a égide do paradigma miasmático, percebeu o entrelaçamento da ocorrência das doenças com as questões ambientais e sociais. Conhecimento que foi indispensável para embasar as grandes reformas urbanas e sanitárias ocorridas no século XIX e que significou, nos países hoje desenvolvidos, um intenso processo de transformações ambientais e sociais que tiveram um imenso impacto na saúde e na qualidade de vida das suas populações $\left(\operatorname{Rosen}^{44}, 1994\right)$. Após um retrocesso ao início do período microbiano, a noção de ambiente ressurge na epidemiologia como parte da tríade ecológica. Assim, na maior parte da história da investigação epidemiológica, a busca das causas das doenças tem sido centrada nos fatores externos ao organismo. Mesmo a denominada epidemiologia molecular traz implícita a idéia de que marcadores biológicos definem padrões orgânicos de maior ou menor susceptibilidade a fatores externos ao organismo (McMichael ${ }^{45}$, 1994). Isto se justifica porque a epidemiologia moderna, dentro dos seus limites, mostra diferenças essenciais com relação à abordagem causal de outras disciplinas que centram o entendimento dos eventos mórbidos apenas no plano das alterações e anormalidades biológicas.

A revisão dos conceitos e das medições da saúde que a epidemiologia utiliza na sua prática de disciplina científica, ajuda a entender alguns dos seus impasses. O conceito sobre o que é saúde tem variado desde noções operativas - a mais primária delas como a simples ausência da doença - até aquelas não operacionalizáveis, tendo como exemplo mais extremado e de profundo conteúdo utópico, a clássica definição da Organização Mundial da Saúde - saúde como o "estado de completo bem estar físico, mental e social". No tocante à medição, etapa imprescindível no processo de produção de conhecimento de uma disciplina que tem suas referências no mundo empírico, os instrumentos atualmente utilizados para mensurar a saúde das populações estão mais próximos das perspectivas operativas e centradas em torno da frequência das doenças (Patrick e Bergner ${ }^{46}$, 1990; Ware ${ }^{47}$, 1995). Esta opção, pela indisponibilidade de outros recursos para medição da saúde, tem várias implicações. Em um processo tautológico, de um lado contribui para a manutenção das referências da epidemiologia centradas em torno da doença, do outro, é a demonstração de que a epidemiologia não conseguiu introduzir nas medidas da saúde das populações o seu patrimônio de conhecimentos sobre o papel causal dos fatores ambientais, culturais e sociais. Esforços têm sido feitos no sentido de romper com esta abordagem centrada no conceito de doença. No plano das idéias, propostas de uma epidemiologia da saúde em substituição à epidemiologia da doença (Terris ${ }^{48}$, 1987) ou de um "modelo salutogênico" em substituição ao "modelo patogênico" dominante (Antonovsky ${ }^{49}, 1979$ ), têm sido apresentadas. No plano da prática, pode-se citar um exemplo recente (Mackenback e col. $\left.{ }^{50}, 1994\right)$ que, fazendo uso de um desenho da epidemiologia moderna, em uma população holandesa, estudou os fatores associados ao estado de saúde auto referido como excelente.

A ênfase analítica no estudo das associações causais, que é uma das marcas da epidemiologia moderna, fundamenta-se, entre outros equívocos, na idéia de que os problemas de saúde estão cristalizados em sistemas classificatórios inquestionáveis e que as doenças são definidas de forma neutra $\mathrm{e}$ objetiva. Questões relacionadas com os sistemas classificatórios dos fenômenos com que opera não recebem maior atenção na epidemiologia moderna. Eventualmente, a questão da classificação é discutida com relação ao diagnóstico das doenças, não se percebendo a importância que o processo de classificar tem na organização do pensamento humano. É evidente que a forma com que classificamos os eventos tem implicações fundamentais sobre o modo pelo qual intervimos no mundo, pois é através dele que organizamos e agrupamos os fe- 
nômenos que percebemos já que, em geral, somos incapazes de compreende-los isoladamente. As classificações são produtos resultantes da forma com que agrupamos os fenômenos que nos circundam e refletem o entendimento das suas semelhanças e das suas diferenças. Segundo Tort ${ }^{51}$ (1989), as classificações são sempre construídas sobre dois pressupostos básicos: as similaridades (metáforas) ou as conectividades, sejam contiguidades, associações ou genealogias (metonímias).

Para agruparmos as doenças, tem-se utilizado por décadas classificações sobre as quais se têm elaborado muito poucas críticas. Dos sistemas classificatórios disponíveis, o mais utilizado é a Classificação Internacional das Doenças - CID, já em sua décima versão. Esta foi gerada a partir de concepções biomédicas, com o princípio classificatório oscilando entre similaridades anatômicas e associações etiológicas. Se entendemos que as doenças são problemas socialmente produzidos e social e historicamente construídos, e não apenas problemas biológicos, verificamos que estes sistemas classificatórios não incluem várias dimensões que fazem parte deste entendimento das doenças, destacando-se os aspectos sociais, culturais e ambientais. Esta preocupação já está presente em Cassel $^{31}$ (1964) quando, por exemplo, questiona o porquê das classificações de doenças colocarem a esquizofrenia ao lado da psicose maníaco-depressiva e não ao lado da tuberculose e do suicídio, já que a esquizofrenia tem com a tuberculose e o suicídio similaridades em termos dos seus determinantes sociais, enquanto que, com a psicose maníaco-depressiva tem apenas vinculação topográfica.

Outra característica, não menos importante, desses sistemas classificatórios é o fato de excluírem vários eventos de saúde, apesar de percebidos por aqueles que os sofrem. Este é um problema enfrentado quotidianamente por todos aqueles que trabalham no cuidado direto com os usuários nos serviços de saúde ou pelos próprios usuários. Uma série de sintomas percebidos, por não ganharem o status de doen- ça e, como consequência, não serem incluídos em tais classificações, permanecem não diagnosticados. A despeito do acúmulo de evidências demonstrando, no plano individual, relações entre modo de vida, psiquê e sintomas físicos, nem sempre classificáveis como doenças e, no plano populacional, a importância da saúde percebida como preditor de eventos de doença e de morte (Mossey e Shapiro $^{52}$, 1982; Kaplan e Cama$\mathrm{cho}^{53}$, 1983), queixas e sintomas percebidos que não encontram abrigo nestes sistemas classificatórios são desqualificados como problemas de saúde.

A integração dos conhecimentos sobre a determinação ambiental, cultural e social das doenças e da saúde, acumulados na história da epidemiologia, aos conhecimentos sobre as formas como os indivíduos e as sociedades percebem seus problemas de saúde e seus sofrimentos, acumulados pela antropologia da saúde, pode servir de base para avanços conceituais sobre a saúde. Etapa fundamental no desenvolvimento de novos sistemas classificatórios que, através de novas metáforas e novas metonímias, expressem o nosso entendimento do processo saúde-doença para além do sistema de referência biológico e no desenvolvimento de novos indicadores que tenham a capacidade de medir dimensões ainda não mensuráveis do processo saúde-doença.

Reencontrar o elo perdido das preocupações da epidemiologia com o ambiente e com a qualidade da vida e atualizar estes vínculos à luz dos imensos conhecimentos acumulados e das necessidades das sociedades contem-porâneas é uma tarefa que tem como consequência não somente reforçar a disciplina, no que se refere às suas preocupações com a população, mas também equacionar desafios teóricos, metodológicos e tecnológicos que a reforçam enquanto disciplina científica.

\section{Avaliação e escolha das intervenções em saúde}

A capacidade de produzir e colocar em uso novas tecnologias voltadas para o cuidado à saúde (drogas, aparelhos, procedimentos e sistemas organizacionais para a 
atenção à saúde) tem crescido exponencialmente. Ao lado do potencial de cura ou de prevenção (nem sempre confirmado) e dos efeitos indesejáveis destas tecnologias estão seus altos e crescentes custos, razão de preocupação de todos aqueles com alguma respon-sabilidade sobre a saúde dos indivíduos ou das populações. A visão dominante de progresso social traz consigo a idéia equivocada de que este progresso ocorre em conseqüência da assimilação de novas tecnologias (Cipolla ${ }^{54}$, 1964; Germani ${ }^{55}$, 1974). No campo da saúde, desde pelo menos os clássicos trabalhos de Illich ${ }^{56}$ (1975) e, principalmente, os trabalhos de McKeown $^{57}$ (1979), paira sobre nossas consciências uma profunda dúvida sobre a real importância destas tecnologias como modificadoras das condições de saúde das populações.

De não menos importância como marco neste campo temos o trabalho de Cochrane $^{58}$ (1971). Este autor, ao constatar que a maioria das tecnologias médicas utilizadas até aquele momento não havia passado por processos de avaliação de sua eficácia, alertou sobre os riscos dessas tecnologias, provocando um imenso impacto sobre o que se concebia até aquele momento como avaliação das mesmas. A importância histórica da posição de Cochrane deve-se ao seu clamor pela obtenção de garantias da eficácia de qualquer intervenção e serviu para estimular o uso dos ensaios aleatorizados nessas avaliações. Os trabalhos de McKeown ${ }^{57}$ e Cochrane ${ }^{58}$ podem ser considerados como abordagens representativas de duas visões extremas sobre as concepções da saúde, das doenças e das formas de modificá-las. A primeira, representando a visão da doença como um processo fundamentalmente social e histórico e, enquanto tal, apenas secundariamente modificável pelas intervenções médicas, e a segunda a visão do corpo como uma máquina biológica que pode ser afetada por problemas disfuncionais - a doença, cuja proteção depende primariamente de intervenções efetivas sobre os seus mecanismos geradores.

Tem-se buscado várias estratégias para demonstrar o quanto as tecnologias, ações e serviços de saúde podem ser eficazes ou efetivos, porém há evidências de que uma parte importante das mesmas, apesar de em uso corrente, não foi adequadamente avaliada. Podem-se apontar como fatores que contribuem para isso: a imensa e exponencialmente crescente quantidade de tecnologias disponíveis, os altos custos de um adequado processo de avaliação, a falta de interesse dos produtores, as incertezas sobre a extrapolação dos estudos de eficácia para outras populações, as insuficiências de ordem metodológicas como a falta de desenhos que permitam avaliações objetivas de certas tecnologias (por exemplo, as cirurgias ou os métodos psicoterápicos ${ }^{59}$. Os ensaios aleatorizados, a forma mais elaborada de avaliação disponível (Power e col. ${ }^{60}, 1994$ ) - para alguns, o modelo de referência na investigação epidemiológica (Horwitz ${ }^{61}$, 1987; Miettinen ${ }^{62}$, 1989) - apresentam, com frequência, resultados discordantes, mesmo quando baseados em desenhos e tamanhos amostrais que lhes garantiriam validade. Como consequência, mesmo no caso de tecnologias que tenham os ensaios aleatorizados como o mais indicado para suas avaliações, a exemplo dos medicamentos e das vacinas, há dificuldades para a formação de consensos que norteiem decisões seguras sobre o uso de cada uma delas. Para compensar as insuficiências dos estudos aleatorizados, novos recursos de avaliação têm sido desenvolvidos e utilizados. Como exemplos, podem-se citar as metanálises e os ensaios com grandes amostras e desenhos simplificados (large sample randomized trials). A metanálise tem por objetivo agregar os resultados de vários estudos sobre uma mesma tecnologia, o que significa, pela soma das amostras de cada estudo isolado, aumentar a amostra global, para em seguida, através de artifícios de análise, estimar seus efeitos médios (Greenland ${ }^{63}$, 1987). Os ensaios com grandes amostras possibilitam uma maior eficiência do estudo e a observação de fenômenos que não seriam observados em estudos com amostras convencionais, como muitos dos efeitos indesejáveis. Porém, para que tenham 
viabilidade operacional, utilizam desenhos mais simplificados, o que pode eventualmente afetar a qualidade dos resultados (Peto e col. ${ }^{64}$, 1993; Barreto e col.65, 1996).

Se todo o esforço de avaliação não tem superado os problemas inerentes à definição da eficácia das tecnologias, maiores ainda são as limitações com relação à avaliação da efetividade. Pois, mesmo tendo níveis aceitáveis de eficácia quando analisadas isoladamente, muitas das tecnologias são pouco efetivas quando utilizadas como parte rotineira de ações, programas e serviços de saúde. A questão torna-se mais complexa e real, embora menos aparente, quando nos deparamos com o problema da efetividade dos programas e serviços de saúde. Estes se constituem em estruturas organizacionais que agregam uma ou mais tecnologias e que, em seu conjunto, formam o complexo prestador de serviços de saúde. Este complexo atua segundo regras de mercado, nem sempre sujeito a normas reguladoras e ao controle social, e que dificilmente poderá vir a ser globalmente avaliado. Entretanto, avaliar a eficácia e a efetividade de, pelo menos, parte das tecnologias, ações ou programas direcionados à cura ou prevenção em saúde é uma tarefa para a qual a epidemiologia dispõe de recursos. Inclusive, ainda que de forma incipiente, tem-se experimentado a aplicação de estudos aleatorizados na avaliação de serviços completos - firm trials - em lugar da avaliação de tecnologias isoladas. A documentação da baixa efetividade de muitas dessas intervenções e o alto custo dos seus limitados benefícios são uma contribuição científica e socialmente relevante da epidemiologia para a melhoria da qualidade e o controle de custos da assistência e da prevenção em saúde. Como exemplo, pode-se citar estudo que avaliou o papel do sistema hospitalar na atenção à diarréia infantil na Região Nordeste do Brasil (Barreto e col.66, 1997). Por problemas relacionados à aces-sibilidade e à qualidade da assistência prestada, observou-se muito baixa efetividade no que concerne à diminuição dos óbitos por esta doença. Isto eleva para níveis proibitivos e injustificá- veis o seu custo-efetividade, desperdiçando recursos que poderiam estar direcionados para programas de prevenção com efetividade já demonstrada.

\section{Causa versus prevenção: algumas conclusões}

Na epidemiologia moderna a medida de risco mais utilizada é o risco relativo, o que mede a força da associação, ou seja a chance de um grupo populacional vir a ter o evento mórbido, relativamente a um grupo de referência. Outras medidas, destacando-se o risco atribuível, de maior interesse para a mensuração populacional do risco e para estimar a sua importância para uma população definida, têm sido secundarizadas. Um fator com baixo risco relativo pode ter grande importância populacional, assim como um fator com alto risco relativo pode ter pequena importância populacional. Os métodos e desenhos de estudo desenvolvidos pela epidemiologia moderna têm-se mostrado extremamente eficientes no estudo de fatores causais com grande força de associação ou com alto grau de especificidade em relação ao seu efeito. Porém, grande parte dos fatores de risco associam-se aos efeitos através de baixos riscos relativos ou de forma pouco específica, razões que contribuem para as inconsistências dos resultados, encontradas em diferentes estudos sobre a mesma questão.

Na epidemiologia, a causa é entendida como um fator ou um conjunto de fatores vinculado à ocorrência de um evento mórbido. Por analogia, conclui-se que a retirada da causa ou a introdução de algo que a neutralize reduzirá a ocorrência do evento. Ação que genericamente se denomina de medida de prevenção. Apesar do caráter empirista da epidemiologia, a causa, por mais real que seja, situa-se no campo do conhecimento, enquanto que a prevenção, resultante do conhecimento sobre as causas, encontra-se no campo da práxis. Aqui ficam definidos dois espaços interdependentes e nem sempre claramente delimitados, o do conhecimento e o da ação - 
a epidemiologia como disciplina científica (que estuda a saúde, a doença e os seus determinantes) e como campo profissional da saúde coletiva (que desenvolve tecnologias e estratégias de prevenção) (Paim e Almeida-Filho ${ }^{67}$, 1998). No primeiro espaço elaboram-se teorias, desenham-se estudos, analisam-se dados, produzem-se informações e conhecimentos. No segundo, a partir do anterior, produzem-se novos conhecimentos, delineiam-se estratégias, concretizam-se ações. No primeiro, os erros são de ordem teórica e metodológica. No segundo, os erros significam vidas, doenças, sofrimentos, ou ainda, custos sociais, econômicos ou políticos.

Enquanto se tenha consolidado a idéia de que grande parte dos fenômenos relacionados à saúde tem múltiplas causas, a construção de modelos multi-causais, a exemplo das redes de causalidade, carece não só de qualquer consistência teórica, assim como tem sido de baixa utilidade operacional por insuficiências no campo metodológico (Krieger $\left.{ }^{7}, 1994\right)$. McCormick e Skrabaneck ${ }^{68}$ (1988), discutindo esta questão, concluem que a qualificação de uma etiologia como multifatorial tem significado, na prática, o desconhecimento da causa. Estes autores sugerem que muitos dos fatores de risco conhecidos venham a ser denominados "marcadores de risco", com o sentido de se evitar expectativas não realistas de prevenção. As estratégias de prevenção que efetivamente são utilizadas, organizam-se a partir de concepções unicausais. No sentido de reafirmar essa perspectiva reducionista, Tesh $^{69}$ (1988) destaca que as práticas atuais de prevenção giram em torno de apenas três modelos fundamentais: o do germe, o do estilo de vida e o ambiental. Para cada um destes modelos existem estratégias de intervenções preventivas correspondentes: vacinas, educação em saúde e normas reguladoras, respectivamente. A idéia primária que se opera na epidemiologia é de que o achado causal gera a prevenção e, somente pelo acúmulo de conhecimentos causais se poderão elaborar novas estratégias de prevenção. Observando-se a história do desenvolvimen- to do conhecimento sobre algumas causas isoladas e o consequente desenvolvimento das ações para a prevenção das mesmas, este processo linear pode eventualmente ocorrer. Entretanto, revendo-se na história da saúde pública as relações entre os modelos causais e os modelos preventivos, conclui-se que esta premissa dificilmente poderá ser generalizada. Se o conhe-cimento da causa antecede a formulação da estratégia de prevenção, os limites preestabelecidos para as estratégias de prevenção têm definido, em uma aparente contradição, o espectro de relações causais a serem objeto de investigação. A desqualificação da determinação social, cultural e ambiental da doença ou de outras teorias causais não ocorreu pelos conhecimentos que produziram, mas sim pelas suas potenciais consequências em termos das estratégias de prevenção que produziram ou poderiam vir a dar origem.

Não há dúvida de que a crise pressentida da epidemiologia moderna é, antes de tudo, uma crise de esgotamento, já que: a) as possibilidades de novos conhecimentos sobre fatores de risco com forças associativas muito altas ou com altos graus de especificidade, com relação ao seus efeitos, estão esgotadas; b) as propostas de prevenção fator a fator têm-se mostrado de limitada eficiência e de difícil implementação; c) com frequência, a avaliação das tecnologias não fornece um quadro completo dos efeitos previstos e imprevistos e, principalmente, os seus efeitos, quando utilizadas como parte de complexos programas de intervenção na saúde; d) por melhor que sejam as intenções e por mais consistente que sejam os conhecimentos disponíveis, a capacidade de se prever o resultado das intervenções que se implementam é, em geral, baixa.

Porém, têm-se algumas convicções. Uma delas é de que sínteses feitas a partir dos conhecimentos existentes têm produzido algumas categorizações lógicas e consistentes que, aplicadas em populações, definem estratos que se diferenciam de outros com relação ao risco de ocorrência de um ou mais eventos mórbidos de im- 
portância. Essas categorias, quando utilizadas como ponto de partida para reorganizar políticas populacionais de prevenção, podem ser de grande utilidade. Assim, podem-se entender os esforços como os de Castellanos $^{70,71}$ (1992; 1997), desenvolvidos por outros (Paim $\left.{ }^{35}, 1997\right)$, de demonstrar que a categorização de populações de acordo com os níveis de condições de vida, definem sub-populações com diferentes níveis de saúde e podem servir de base para a definição de prioridades nas ações de proteção e promoção à saúde. Porém, outros recortes também podem definir subgrupos populacionais com relação à ocorrência de eventos de saúde. Como exemplo pode-se utilizar o caso de um recente e denso relatório sobre as relações entre alimentos, nutrição e câncer, produzido com o objetivo de intensificar a prevenção deste grupo complexo de patologias (World Cancer Research Found ${ }^{72}$, 1997). A análise detalhada das evidências científicas existentes, advindas principalmente de estudos epidemiológicos, que suportam ou não possíveis associações causais entre os vários alimentos e fatores nutricionais e os vários tipos de câncer, resultou na proposição de intervenções organizadas em torno de apenas 14 recomendações, cada uma delas definindo ações em nível populacional e correspondentes orientações em nível individual. Estas recomendações são produto do esforço de sistematização das infinitas possibilidades de prevenção que resultam do conhecimento ou desconhecimento existentes sobre as associações causais entre fatores nutricionais e alimentares específicos e canceres específicos. Estimou-se que o seguimento dessas recomendações poderia levar à redução de 30 $40 \%$ do total de casos de câncer no mundo(3-4 milhões de casos por ano), além de ter repercussões positivas sobre a ocorrência de uma série de outras patologias relacionadas à alimentação e fatores nutricionais. A opção pela prevenção centrada em fatores específicos, além da baixa viabilidade enquanto política de saúde, seria de difícil entendimento e utilização por indivíduos e por populações.
Susser e Susser ${ }^{11}(1996)$ previram o advento de uma nova era na epidemiologia que, a partir da ruptura com a visão simplista, dicotômica que se construiu, será estruturada sobre os elos relacionais entre os vários níveis da realidade. A esta nova era denominaram de eco-epidemiologia, a ser constituída sobre um novo paradigma - as "caixas chinesas". Este novo paradigma seria resultante da síntese de conhecimentos gerados em dois níveis. O macro, com o estudo dos fenômenos em nível da população e das sociedades, e o micro, com o estudo dos fenômenos que ocorrem no nível molecular. O novo paradigma seria essencialmente integrador e harmonizador destes níveis do conhecimento. Os métodos e técnicas que permitirão concretizar tais possibilidades estão apenas enunciados, o que segundo os autores não se constitui em problema pois, de maneira similar, no início da era da epidemiologia das doenças crônicas os desenhos de estudos e recursos de análise, hoje rotineiramente utilizados, apenas despontavam.

A crítica na ciência não tem, em geral, a pretensão de extinguir o velho e substituí-lo por algo novo. Pretende, sim, superar as referências paradigmáticas existentes no momento em que estas não se mostram capazes de resolver questões que lhes são apresentadas. Neste sentido, o que aqui se denominou de epidemiologia moderna continuará tendo, por muito tempo, papel importante no desenvolvimento de conhecimento sobre as causas das doenças (Savitz, ${ }^{73}$ 1994). Porém, da mesma forma que aconteceu em outras disciplinas científicas, a superação da epidemiologia moderna implica obrigatoriamente em retirarlhe a capacidade de continuar sendo o eixo estruturante da produção do conhecimento epidemiológico.

É difícil acreditar que, em um tempo observável, a epidemiologia poderá responder a todas as questões e problemas postos para ela, por mais que seus paradigmas sejam atualizados. Isso não diminui a sua importância e mostra a pertinência de se continuar elaborando e reelaborando questões, perplexidades e críticas. Tam- 
bém, não concede o direito da ignorância com relação ao conhecimento existente ou da postergação de in-tervenções e outras ações que, em um dado momento, apresentem-se como neces-sárias. Neste contexto é que se situam os pragmáticos, no momento em que, com conhecimentos deficientes e em condições adversas, conseguem propor melhorias nas condições de saúde da população. Na sua tensão entre disciplina científica e campo profissional, a epidemiologia traz à tona, para os seus praticantes, independente de onde estejam situados, os desafios da dialética entre o sonhar e o fazer, entre a utopia e a realidade, entre a técnica e a política.

Repensar a forma de conceber a prevenção constitui-se um dos grandes desafios de uma epidemiologia da saúde coletiva. No processo de produção científica, quando faltam recursos analíticos mais adequados ou quando se quer aprofundar a análise de um fator, pode-se isolá-lo e testá-lo fora do seu sistema original. Porém, no momento da intervenção já não se opera com modelos, mas sim com a realidade em toda a sua complexidade. $\mathrm{Na}$ transmutação de conhecimentos gerados a partir de bases conceituais deficientes e de modelos reducionistas para ações e intervenções em realidades, por natureza complexas, ocorrem muitos erros e frustram-se expectativas com relação aos efeitos ou mudanças esperadas (Dorner ${ }^{74}$, 1996). Para tornar mais intricada a questão, deve-se ter em conta o fato de que na prevenção atua-se sobre indivíduos e populações que, em geral, não são os mesmos a partir das quais os riscos foram estimados. É operação frequente a utilização de riscos estimados em um dado contexto para projetar-se estimativas do impacto das intervenções na redução dos riscos em um outro contexto. Esta passagem provoca o aumento das incertezas, e mesmo implicam no aumento dos limites de confiança originalmente estimados.

Vive-se em um momento de grandes tensões epistemológicas. Na história do conhecimento idealizou-se um mundo linear, visão que felizmente está em declínio. As relações causais estabelecidas em bases dicotômicas, lineares, unidirecionais, exclusivamente quantitativas e com baixa capacidade preditiva são questionadas. Muitos sentem a necessidade de percepção, registro e análise dos elementos não mensuráveis ou qualitativos da saúde (Trostle ${ }^{75}, 1986$; Baum $^{76}$, 1995). Pela dinâmica do conhecimento e no prenúncio de uma nova era e não por simples modismo, tópicos como estudos ecológicos (Morgenstern ${ }^{77}, 1995$ ), quase-experimentos (Behi e Nolan ${ }^{78}, 1996$ ), caos (Philippe ${ }^{79}$, 1992), transdisciplinaridade (Almeida-Filho ${ }^{80}, 1997$ ), lógica fuzzy (Corson $\left.^{81}, 1996\right)$, fractais (Anderson e col. ${ }^{82}$, 1997), complexidade (Schramm e Castiel ${ }^{83}$, 1992; Marques $^{84}$, 1995; Castiel ${ }^{85}$, 1996), estatística Bayesiana (Etzioni e Kadane ${ }^{86}$, 1995), modelos em múltiplos níveis (Von Korf e col. ${ }^{87}$, 1992; Fucks e Victora ${ }^{88}$, 1997), redes neurais (Hammad e col. ${ }^{89}, 1996$ ) etc. começam a ter cada vez mais usuários e adeptos na comunidade epidemiológica. Em uma área tradicional que é a epidemiologia das doenças infecciosas e parasitárias, com base em conceitos como dinâmica de populações e razão de reprodução básica, constroem-se modelos matemáticos cada vez mais complexos e pouco accessíveis aos não iniciados que incluem número crescente de fatores na busca de simulações mais aproximadas da realidade onde a doença ocorre (Scott e Smith ${ }^{90}$, 1994).

O epidemiologista adequado ao presente deve transitar entre as definições e usos tradicionais da disciplina e uma série de novos conceitos que vêm sendo continuamente decodificados e assimilados; deve dialogar com as experiências inovadoras que se constituam em contribuições no fortalecimento dos vínculos da epidemiologia com seus propósitos fundamentais e com a saúde coletiva; deve participar da construção das novas bases conceituais e metodológicas que irão permitir o desenvolvimento de conhecimentos e novas possibilidades de prevenir os eventos mórbidos e amenizar os sofrimentos humanos. Para intervir no presente, deve buscar, no conhecimento epidemiológico até então produzido, evidências que tornem possível 
o desenvolvimento de alternativas de prevenção tecnicamente viáveis, de grande impacto populacional e efetivas sobre o maior número possível de problemas de saúde. Porém, que também sejam social e individualmente aceitáveis e politicamente realizáveis. A implementação de muitas intervenções somente é possível após mudanças ou redefinições no campo político. As vinculações com outros profissionais da saúde coletiva devem se dar pela construção de afinidades em torno de tudo aquilo que diga respeito à prevenção.

Nesta direção a epidemiologia reconstituirá suas bases teóricas e metodológicas, fundadas em princípios éticos e em justificativas morais que direcionem seus esforços para entender e contribuir na redução das desigualdades na saúde, na melhoria da qualidade de vida dos indivíduos e das populações e na seleção das tecnologias de saúde, evitando a exposição indiscriminada dos indivíduos e das populações a intervenções com baixa efetividade ou que induzam novas doenças e novos sofrimentos. Tudo isto, porém, ganhará um maior sentido quando articulado a um outro arca- bouço que está sendo paulatinamente construído, o qual busca compreender as razões da intensa dinâmica temporal dos eventos de saúde nas populações humanas, bem como dos seus determinantes e, mesmo, da efetividade das intervenções (Omran, ${ }^{91}$ 1971; McKeown ${ }^{57}$, 1979; Caldwell ${ }^{92}$, 1993; Barreto e col. ${ }^{93}$, 1994). Esta articulação tende a relativizar o papel dos conhecimentos obtidos em momentos isolados e colocá-los em uma perspectiva histórica, possibilitando a produção de muitos dos conhecimentos que necessitamos.

\section{Agradecimentos}

Gostaria de agradecer aos colegas Jainilsonm Paim, Carmen Teixeira, Naomar Almeida e Estela Aquino por seus comentários em aspectos importantes do texto. A apresentação de versões preli-minares no V Congresso Brasileiro de Saúde Coletiva, em 1997, em Águas de Lindóia-SP, e no IVCongresso Brasileiro de Epidemiologia, em 1998, no Rio de Janeiro, serviram de estímulo e foram vitais no amadurecimento da versão aqui apresentada.

\section{Referências}

1. Last JM. editor. Dictionary of epidemiology. New York: Oxford University Press; 1988.

2. Rothman KJ.Modern epidemiology. Boston:Little, Brown; 1986.

3. Almeida Filho N. A clínica e a epidemiologia. Salvador: APCE/ABRASCO; 1992.

4. Barata RB, Barreto ML. Algumas questões sobre o desenvolvimento da epidemiologia na América Latina. Ciênc Saúde Coletiva 1997; 1:70-9.

5. Breilh J. A epidemiologia na humanização da vida: convergências e desencontros das correntes. In: Barata RB , Barreto ML, Almeida Filho N, Veras RP, editores. Equidade e saúde: contribuições da epidemiologia. Rio de Janeiro: Editora FIOCRUZ/ABRASCO; 1997. p. 23-37.

6. Long AF.Understanding health and disease: towards a knowledge base for public health action. Leeds: University of Leeds; 1993.

7. Krieger N. Epidemiology and the web of causation: has anyone seen the spider? Soc Sci Med 1994; 39: 887-903.

8. McMichael AJ.The health of persons, populations and planets: epidemiology comes full circle. Epidemiology 1995; 6: 633-6.
9. Pearce N. Traditional epidemiology, modern epidemiology and public health. Am J Public Health 1996;86:678-83.

10. Susser M, Susser E. Chosing a future for epidemiology. Part I: Eras and paradigms. Am J Public Health 1996; 86:668-73.

11. Susser M, Susser E. Choosing a future for epidemiology:II. From black box to chinese boxes and ecoepidemiology. Am J Public Health 1996; 86:674-7.

12. Shy CM. The failure of academic epidemiology: witness for the prosecution. Am J Epidemiol 1997; 145:479-87.

13. Susser M. Epidemiology in the United States after world war.ll: the evolution of the technique. Epidemiol Rev 1985; 7:147-77.

14. Barreto ML. A epidemiologia sua história e crises: notas para pensar o futuro. In: Costa DC, editor. Epidemiologia: teoria e objeto. São Paulo: Hucitec/ABRASCO; 1990.p. 19-38.

15. Miettinen OS. Theoretical epidemiology: principles of occurrence research in medicine. New York: John Willey and Sons; 1985.

16. Rose G. The strategy of preventive medicine. Oxford:Oxford Unversity Press; 1992.

17. Krieger N, Zierler S. What explains public's health? A call for epidemiologic theory. Epidemiology 1996; 7:107-9. 
18. Wing S. Limits of epidemiology. Med Global Surv 1994; 1 : 74-86.

19. Dean K, Hunter D. New directions for health: towards a knowledge for public health action. Soc Sci Med 1996;42: 745-50.

20. Evans R, Stoddart G. Introduction. In: Evans R, Barer M, MarmorT, editors. Why are some people healthy and others not? The determinants of health of populations. New York: Aldine de Gruyter; 1994. p. 3-26.

21. Angell M. The interpretation of epidemiologic studies[Editorial]. N Engl J Med 1990; 323: 823-5.

22. Taubes G. Epidemiology faces its limits. Science 1995; 269 : 164-9.

23. McMichael A J. Setting environmental exposure standards: the role of the epidemiologist. Int J Epidemiol 1989; 16:10-6.

24. Solla J S S P. Problemas e limites da utilização do conceito de classe social em investigações epidemiológicas. Cad Saúde Pública 1996; 12:207-16.

25. Liberatos P, Link BG, Kelsey JL. The measurement of social class in epidemiology. Epidemiol Rev 1988; 10:87-121.

26. Cochrane SH, Leslie J, O'Hara DJ. Parental education and child health: intracounty evidence. Health Policy Educ 1982; 2: 213-50.

27. Krieger N, Fee E. Man-made medicine and women's health: the biopolitics of sex/gender and race/ethnicity. Int J Health Service 1994;24:265-83.

28. Wilkinson RG. Unhealthy societies: the afflictions of inequalities. London: Routledge; 1996.

29. Engels F. The condition of the working class in England. Moscou: Progress Publishers; 1977.

30.Taylor R, Rieger A. Rudolf Virchow and the thifus epidemia in Upper Silesia: an introduction and translation. Sociol Health Ilness 1984; 6:210-7.

31. Cassel J. Social science theory as a source of hypothesis in epidemiologic research. Am J Public Health 1964; 54 : 1482-8.

32. Cassel J.The contribution of the social environment to host resistance. Am J Epidemiol 1976; 104:107-23.

33. Wilkinson R. Relação internacional entre equidade de renda e expectativa de vida. In: Barata RB, Barreto $\mathrm{ML}$, Almeida Filho N, Veras RP, editores. Equidade e saúde: contribuições da epidemiologia. Rio de Janeiro:Editora FIOCRUZ/ABRASCO; 1997. p. 103-20.

34. Stephens $C$. Healthy cities or unhealthy islands? The health and social implications of urban inequalities. Environ Urban 1996; 8: 9-30.

35. Paim JP. Abordagens teórico-conceituais em estudos de condições de vida e saúde: notas para reflexão e ação. In: Barata RB, editor. Condições de vida e situação de saúde. Rio de Janeiro: ABRASCO; 1997. p. 7-30.

36. Akerman M. Metodologia de construção de indicadores compostos: um execício de negociação intersetorial. In:. Barata RB, editor. Condições de vida e situação de saúde. Rio de Janeiro: ABRASCO; 1997.p. 95-114.
37. Borell C. Métodos utilizados no estudo das desigualdades em saúde. In:Barata, RB editor. Condições de vida e situação de saúde. Rio de Janeiro: ABRASCO; 1997. p. 95-114.

38. Scwarcwald C, Leal MC. Estatística espacial na análise exploratória de dados epidemiológicos. In: Barata RB editor.Condições de vida e situação de saúde. Rio de Janeiro: ABRASCO; 1997. p. 251-70.

39. Schwartz S. The fallacy of the ecological fallacy: the potential misuse of a concept and its consequence. Am J Public Health 1994; 84:819-24.

40. Barreto ML. Carmo EH. Mudanças em padroes de morbimortalidade: conceitos e metódos. In: Monteiro CA, editor. Velhos e novos problemas no Brasil:a evolução do país e de suas doenças. São Paulo:Hucitec/ABRASCO; 1995. p. 17-30.

41. Sloggett $A$, Joshi $H$. Higher mortality in deprived areas: community or personal advantages. BMJ 1994; 309: 1470-4.

42. Vagero $D$. Health inequalities as policy issues: reflections on ethics, policy and public health. Sociol Health IIIness 1995; 17: 1-19.

43. Goldbaum M. A epidemiologa em busca da equi-dade em saúde. In: Barata RB, Barreto ML, Almeida Filho N, Veras RP, editores. Equidade e saúde:contribuições da epidemiologia. Rio de Janeiro: Editora FIOCRUZ/ABRASCO; 1997. p. 63-80.

44. Rosen G.Uma história da saúde pública. São Paulo: Ed. UNESP/Hucitec/ABRASCO; 1994.

45. McMichael AJ. Molecular epidemiology. New pathway or new travelling companion. Am J Epidemiol 1994; 140:1-11.

46. Patrick DL, Bergner M. Measurement of health status in the 1990. Annu Rev Public Health 1990; 11:165-83.

47. Ware JE, Jr. The status of health assessment 1994. Annu Rev Public Health 1995; 16:327-54.

48. Terris M. La revolución epidemiológica y la medicina social. México: Siglo Veintiuno; 1987.

49. Antonovsky A. Health, stress and coping: new perspectives on mental and physical well-being. San Francisco:JosseyBass Publishers; 1979.

50. Mackenback JP, Van Den Bos J, Joung IA, Van Der Mheen $H$, Stronks K. The determinants of excelent health: different from the determinants of ill-health. Int J Epidemiol 1994; 23: 1273-81.

51. Tort P. La raison classificatoire. Paris:Aubier; 1989.

52. Mossey JM, Shapiro E. Self-related health: a predictor of mortality among the elderly. Am J Public Health 1982; 72 : 800-8.

53. Kaplan, GA, Camacho T. Perceived health and mortality: a nine year follow-up of the human population laboratory cohort. Am J Epidemiol 1983;117:292-304.

54. Cipolla CM. The economic history of the world population. Baltimore: Penguim; 1964.

55. Germani G. Sociologia da modernização. São Paulo:Mestre Jou; 1974.

56. Illich I. Medical nemesis. London:Calder and Boyars; 1975.

57. McKeown T. The role of medicine:dream, mirage or nemesis? Oxford: Basil Blackwell; 1979. 
58. Cochrane A L.Efficacy and effectiveness:random reflections. Leeds:The Nuffield Provincial Hospitals Trust; 1971.

59. US Congr. Off.Technol. Assess., 1994. Identifying Health Technologies that Work. Searching for Evidence.Washington, DC: US GPO.

60. Power EJ, Tunis SR, Wagner JL. Technology assessment and public health. Annu Rev Public Health 1994; 15:561-79.

61. Horwitz R. The experimental paradigm and observational studies of cause-effect relationships in clinical medicine. J Chron Dis 1987; 40:91-9.

62. Miettinen OS. The clinical trial as a paradigm for epidemiologic research.J Clin Epidemiol 1989;42:491-6.

63. Greenland S. Quantitative methods in the review of epidemiologic literature. Epidemiol Rev 1987; 9:1-30.

64. Peto R, Collins R, Gray R. Large-scale randomized evidence: large, simple trials and overview of trials. In: Warren KS, Mosteler F,editors. Doing more good than harm: the evaluation of health care interventions. New York: New York Academy of Sciences; 1993. p. 314-40.

65. Barreto ML, Dourado MIC, Martins SP, Rodrigues L, Hijjar, MA, Maia MLS. Avaliação da segunda dose do BCG na idade escolar: um protocolo de pesquisa. Inf Epidemiol SUS 1996; 5: 59-68.

66. Barreto M, Mendes CMC, Strina A, Santos C, Ferreira LV. Contribuição da assistência hospitalar no decréscimo da mortalidade em crianças na região Nordeste. In: Anais do $5^{\circ}$ Congresso Brasileiro de Saúde Coletiva; 1997; Águas de Lindóia-SP. Rio de Janeiro: ABRASCO; 1997. p. 6.

67. Paim, JS, Almeida Filho N. Saúde coletiva: uma nova "saúde pública" ou campo aberto a novos paradigmas. Rev Saúde Pública 1998; 32:299-316.

68. McCormic J, Skrabanek P. Coronary hearth disease is not preventable by population interventions. Lancet 1988; 2(8621):839-41.

69. Tesh SN. Hidden arguments: political ideology and disease prevention policy.London: Rutgers University Press; 1988.

70. Castellanos PLC. Sistemas nacionales de vigilância de la situación de la salud segun condiciones de vida y del impacto de las acciones de salud y bienstar. Washington (DC): OPS/OMS; 1992.

71. Castellanos PL. Epidemiologia, saúde pública, situação de saúde e condições de vida. Considerações conceituais. In: Barata RB, editor.Condições de vida e situação de saúde. Rio de Janeiro: ABRASCO; 1997.p. 31-76.

72. World Cancer Research Found. Food, nutrition and the prevention of cancer: a global perspective.Washington DC: WRCF/AICR; 1997.

73. Savitz D A. In defense of the "black box" epidemiology. Epidemiology 1994; 5:550-5.

74. Dorner D. The logic of failure. New York: Metropolitan Books; 1996.

75. Trostle J. Anthropology and epidemiology in the twentieth century: a selective history of colaborative projects and theoretical affinities. In: James CR, Stall R, Gifford SM, editors. Anthropology and epidemiology. Dordrecht: D. Reidel Publ.; 1986. p. 59-96.
76. Baum F. Researching public health: behind the qualitativequantitative methodological debate. Soc Sci Med 1995; 40: 459-68.

77. Morgenstern H. Ecological studies in epidemiology: concepts, principles and methods. Annu Rev Public Health 1995; 16:61-81.

78. Behi R, Nolan M. Quasi-experimental research designs. Br J Nurs 1996, 5:1079-81.

79. Philippe P. Chaos, population biology, and epidemiology: some research implications. Hum Biol 1992; 65: 525-46.

80. Almeida-Filho N.Transdisciplinaridade e saúde coletiva. Ciênc Saúde Coletiva 1997; 2:5-20.

81. Corson SL. Increased risk from third-generation progestogens: fuzzy logic or fuzzy science?[Editorial]. J Reprod Med 1996;41:711-2.

82. Anderson JL, Karagounis LA, Stein KM, Moreno FL, Ledingham R, Hallstrom A. Predictive value for future arrhythimic events of fractal dimen-sion, a measure of time clustering of ventricular premature complexes, after myocardial infarctation. J Am Coll Cardiol 1997; 30:226-32.

83. Schramm FR, Castiel D. Processo saúde/doença e complexidade em epidemiologia. Cad Saúde Pública 1992; 8: 379-90.

84. Marques MB. Doenças infecciosas emergentes no reino da complexidade: implicações para as políticas científicas e tecnológicas. Cad Saúde Pública 1995; 10:285-314.

85. Castiel D. Moléculas, moléstias, e metafóras: o senso dos humores. São Paulo:Unimarco Editora; 1996.

86. Etzioni RD, Kadane JB. Bayesian statistical methods in public health and medicine. Annu Rev Public Health 1995; 16: $23-41$

87. Von Korf M, Koepsell T, Curry S, Diehr P. Multi-level analysis in epidemiologic research on health behaviors and outcomes. Am J Epidemiol 1992;135:1077-82.

88. Fucks SC, Victora CG. Técnica de análise de dados para estudos de condições de vida e situação de saúde. Análise hierarquizada aplicada a investigação de fatores de risco para agravos à saúde infantil. In: Barata RB, editor. Condições de vida e situação de saúde. Rio de Janeiro: ABRASCO; 1997. p. 271-6.

89. Hammad TA, Abdel-Wahab MF, DeClaris N, El-Sahly A, ElKady N, Stricklnd G T. Comparative evaluation of the use of artificial neural networks for modelling the epidemiology of schistosomiasis mansoni. Trans R Soc Trop Med Hyg 1996; 90: 372-6.

90. Scott ME, Smith G, editors. Parasitic and infectious disease: epidemiology and ecology.San Diego:Academic Press; 1994.

91. Omran AR. The epidemiologic transition: a theory of the epidemiology of population change. Milbank Mem Fund Q 1971; 49: 509-83.

92. Caldwell J. Health transition: the cultural, social and behavioural determinants of health in the third world. Soc Sci Med 1993; 36: 125-35.

93. Barreto ML, Carmo EH, Noronha CV, Neves RBP, Alves PC. Mudanças dos padrões de morbimortalidade: uma revisão crítica das abordagens epidemiológicas. Physis. Rev Saúde Coletiva 1994;3:127-46 


\section{Debate sobre o artigo de Maurício L. Barreto \\ Debate on the paper by Maurício L.Barreto}

\section{O resgate da epidemiologia na "crise" da Saúde Pública}

\section{Moisés Goldbaum}

Departamento de Medicina Preventiva da FMUSP

O artigo apresentado por Maurício L. Barreto aborda um assunto instigante, trazendo à cena o debate, ou melhor, repondo a discussão sobre a epidemiologia, seus compromissos e suas perspectivas, bem como apresenta um elenco de desafios que a disciplina enfrenta e que merecem ser devidamente considerados.

Propugnar por uma epidemiologia da Saúde Coletiva apresenta-se como uma proposta fundamental e estratégica para a mesma, procurando recuperar a sua tradição enquanto uma das bases nas quais sempre se assentou ou deveria se assentar a tradicional Saúde Pública. Aos elementos apresentados por Barreto, poucos eu teria a acrescentar, haja vista a extensa e bem realizada revisão bibliográfica que o tema exige, bem como o nível de detalhe na exposição, em especial, das cinco formas de expor e interpretar a crise da disciplina na sua relação com a Saúde Coletiva.

A grande indagação suscitada pelo artigo pode referir-se à ausência de uma discussão ancorada no que se pode denominar de "crise" da Saúde Coletiva ou Saúde Pública. Nos últimos anos os debates sobre essa crise, desde aquele proporcionado pela Organização Panamericana de Saúde em 1992 ${ }^{1}$, têm se realizado com diferentes enfoques e em diferentes instâncias, mas sem proporcionar respostas suficientemente iluminadoras de novos caminhos. Pode-se supor, a partir da realidade vivenciada, que a atividade do profissional de saúde pública estaria defasada e não respondendo às novas demandas postas tanto pelo processo de reorganização dos serviços de saúde, como pelas próprias necessidades de saúde das populações humanas. Essa situação não é nova, nem específica do país, pois essa denúncia, com repercussões no continente americano, já constava no debate publicado em 1992.

Nessa circunstância, a análise feita se enriqueceria bastante se pudesse ser referenciada às definições e orientações que se buscam para a Saúde Coletiva contemporânea. Estou propondo e sugerindo essa discussão, tomando para base de reflexão um paralelo que ocorre com a incorporação, que a Clínica vem fazendo, das técnicas epidemiológicas no tratamento de seus problemas técnico-científicos. Todo o movimento que se gerou em torno dessa questão, especialmente no nosso meio, ocultou, por razões diversas, entre outras tantas importantes, aquelas questões referentes ao seu significado e especificidade (não vou tratar, por exemplo, do embate ideológico, que é importante, mas não cabe nesse momento). A atuação e práticas clínicas vêm sofrendo modificações substanciais, determinadas por diferentes fatores, entre os quais se destaca a incorporação de novas tecnologias, e que explicam a necessidade das novas abordagens técnicas referentes aos seus novos e velhos problemas dos doentes, ao lado da busca do estabelecimento de uma melhor racionalidade de suas atividades. A incorporação das técnicas epidemiológicas, ou do instrumental da metodologia científica, à Clínica, procura responder às necessidades postas pela disciplina e identificadas, contemporaneamente, pelos profissionais e estudiosos da área. Há uma correspondência entre essas novas posturas metodológicas e as necessidades postas pelas indagações clínicas. A discussão sobre os benefícios e desvios que isso acarreta não cabe neste debate; vale o destaque para a articulação

1 OPS. La crisis de la Salud Publica. Reflexiones para el debate. Washington, DC. Publ. Cient. 540, 1992. 
entre essas disciplinas (aliás, se está privilegiando a interdisciplinariedade como um movimento necessário!) e da revalorização que ambas alcançam, em especial a Clínica, no plano técnico-científico e, talvez, as técnicas epidemiológicas, no plano político (simbiose perfeita entre disciplinas!). Vale, também, destacar alguma impropriedade, assumida por alguns autores referidos por Barreto, de que essas abordagens tomando o indivíduo por base respondam a todas as necessidades de saúde, incluindo aquelas de natureza coletiva. Isso talvez seja uma das fortes razões pelas quais se possa explicar o "afastamento" da Epidemiologia de sua origem, a Saúde Coletiva.

Esse paralelo está sendo apresentado pois oferece a oportunidade para apontar que a crise da Epidemiologia pode estar caminhando junto à crise da Saúde Pública. Considerando, a partir dessa última, uma "falta de definição" mais precisa de seu objeto, a própria Epidemiologia (permitamme aqui fazer uma especulação) estaria sem todos os elementos necessários e suficientes para repensar o seu, enquanto disciplina central daquela. Em outros termos, se está havendo uma "adequação" entre técnicas de análise epidemiológicas e as investigações sobre os indivíduos doentes, cabe indagar se a crise identificada por Barreto não se refere a essa ausência de "adequação" de objetos no campo da Saúde Coletiva. Tudo leva a crer que a preocupação com as questões da assistência médica estão a ocupar tempo substancial na implementação das políticas de saúde, impedindo concepções inovadoras e atualizadas sobre a saúde propriamente dita, permitindo sua melhor identificação e especificação.

Não estão sendo propostas "distintas" epidemiologias, tal como se vem observando através das múltiplas adjetivações que ela vem recebendo; trata-se de definir com precisão o(s) objeto(s) com que se trabalha e consequentemente identificar os instrumentos, técnicas e métodos a serem utilizados. Shy, citado por Barreto, faz referência à macroepidemiologia, o que permite lançar a idéia de diferentes níveis de atuação e compreensão; isto, longe de repre- sentar qualquer valorização deste ou daquele conhecimento, implica reconhecer níveis diferentes de problemas e, portanto, utilização e interação distintas de técnicas, métodos e conhecimentos, adequados às questões que se formulam e se pretende responder.

Outra questão suscitada por Barreto diz respeito ao papel da epidemiologia, ou do epidemiologista, na redução das desigualdades relativas ao risco de adoecer, ou seja, em última instância, seu papel nas mudanças sociais. Remete à necessidade de identificação dos seus limites e potenciais: reitera-se aqui a posição de que o desnudar as desigualdades em saúde, implica a utilização tanto do conhecimento classicamente traçado (exemplos existem de trabalhos que permitiram estabelecer relações, nas quais se identifica como as desigualdades nas possibilidades de consumo acarretam diferenciais importantes nos níveis de saúde de diferentes grupos populacionais), quanto daquele a ser gerado por novas categorias pensadas na contemporânea Saúde Pública. Sem descartar o conhecimento gerado pelo nível individual, no qual as categorias clínicas são as dominantes (o que, em princípio, responde às necessidades da atenção médica individual), à epidemiologia cabe, prioritariamente, a geração de conhecimentos proporcionados no nível coletivo com novas possíveis categorias, de natureza coletiva, tanto nas conseqüências, ou se preferirem nas variáveis dependentes (os novos tratamentos dados à violência, incluindo aqui a droga adição, ou mesmo a introdução de categorias como gênero, mostram-se caminhos promissores), quanto na própria forma de compreender a conformação dos grupos sociais (a literatura científica nacional e internacional vem procurando cobrir esses aspectos), promovendo a atualização de objetos da Saúde Pública e de modo concomitante da Epidemiologia. Assim mesmo, a efetivação do "seu compromisso com mudanças efetivas nos níveis de saúde da população" não prescinde do conjunto das informações geradas nos diferentes campos disciplinares. 
Embora Barreto exponha uma "crise de formulações teóricas” e as fundamente, ele mesmo aponta para as novas perspectivas teóricas ou metodológicas que se abrem com a adoção de novos "tópicos como estudos ecológicos, quase-experimentais, caos, transdisciplinaridade, lógica fuzzy...”. Trata-se, aqui, de identificar a concepção de teoria, haja vista, a incorporação de novas teorias do terreno da quantificação, observada pela Epidemiologia. Entretanto, a emergência dessas novas formas de organizar o pensamento epidemiológico nasce da identificação de questões que estão a merecer tratamentos mais complexos e que, de certa forma, vem desafiando mais diretamente parte do meio acadêmico, e menos os sanitaristas, na medida da ausência, para estes últimos, de uma perspectiva mais claramente definidora de sua atuação e repercussão. Nessa perspectiva, pode-se apontar uma evolução teórica da disciplina, favorecida até pelos meios computacionais, e uma necessidade de promover uma revisão e atualização dos níveis de análise das informações geradas por esses novos tópicos.

$\mathrm{O}$ texto de Barreto é bem-vindo. As minhas divergências com as teses apresentadas são de pequena monta, como se pode depreender desta análise. Deve ser ressaltado o caráter científico com que as apresenta, oferecendo uma ótima oportunidade para rever esse debate que está, de certa forma, negligenciado ou, talvez seria melhor dizer, não suficientemente valorizado. Isto está a exigir um claro posicionamento da comunidade para repor a epidemiologia novamente no epicentro das decisões técnico-políticas em saúde.

\section{A síndrome da gafieira (quem está fora não entra e quem está dentro não sai): comentários a "por uma epidemiologia da saúde coletiva"}

\section{Cláudio José Struchiner Programa de Computação Eletrônica da Fundação Oswaldo Cruz, Rio de Janeiro}

O ensaio de Maurício L. Barreto (MLB) propõe uma epidemiologia para a saúde coletiva. Esta proposta baseia-se na identificação de uma crise da epidemiologia. Este não é um ensaio isolado, sendo o tema recorrente na literatura epidemiológica, em particular a brasileira. A recorrência do tema levanta uma série de especulações com possíveis implicações para a organização do campo da epidemiologia em nosso país. Em meus comentários, portanto, procurarei explorar não só as teses do ensaio de MLB mas também a estrutura do pensamento da crise da epidemiologia.

\section{A estrutura do pensamento da crise da epidemiologia}

A conceituação de "epidemiologia" (ou alguma de suas versões, a moderna no caso presente) constitui-se invariavelmente no ponto de partida para as críticas futuras.
Esta construção baseia-se no uso corriqueiro da palavra epidemiologia quer em livrotextos, quer em um conjunto tradicional de revistas científicas dedicadas ao campo, quer na prática de profissionais ligados a instituições (nacionais ou internacionais) normativas da área da saúde. Ao agirem desta forma, os críticos da epidemiologia são obrigados, direta ou indiretamente, a optar por uma delimitação específica da área de conhecimento em questão, entre tantas outras possíveis. Desde logo observa-se a arbitrariedade desta escolha, cabendo então a questão: Seriam as proposições destes autores robustas a definições alternativas de seu objeto de "ataque"?

A questão sobre a definição do que é epidemiologia, ou sua versão particular, torna-se ainda mais ambígua quando observamos que a crise dos "paradigmas" da epidemiologia é constituída de elementos 
faltantes ou "deficiências" que ocorrem no interior da disciplina, mas o "processo de produção de conhecimentos alternativos ..., em muitos momentos...," acontece "fora do núcleo central da disciplina ...". No presente ensaio, estes elementos são: (1) uma crise do seu paradigma dominante; (2) uma crise na sua capacidade de formulação teórica; (3) uma crise resultante da rutura dos seus compromissos históricos; (4) uma crise da relação com a prática da saúde pública; e (5) uma crise da capacidade explicativa, gerada pelo conflito de resultados.

Por que invocar a dualidade dentro vs fora e não considerar a produção do conhecimento como um todo contínuo, sem a existência de barreiras delimitadoras e genuinamente multidisciplinares? Ao contrário da axé music e dos trios elétricos, a esta postura eu, carinhosamente, denominaria de a síndrome da gafieira já que quem está dentro não sai e quem está fora não entra. Junto com a questão acima, a leitura do ensaio propõe outras indagações sobre a natureza da estrutura do pensamento da crise da epidemiologia. Após a opção pelo comportamento territorialista, a epidemiologia passa a ser descrita também como possuindo uma "posição peculiar", ou "diferenças essenciais", ou ainda como "disciplina básica da saúde pública”, visões certamente bastante lisonjeiras de si própria.

Estes dois elementos, o territorialismo e a vaidade, identificáveis na estrutura do pensamento da crise da epidemiologia, poderiam ser considerados como inofensivos ou apenas objetos de curiosidade acadêmica, não fosse pelas implicações ao nível da organização do campo em nosso meio. Por exemplo, em um movimento recente de reorganização da estrutura de pós-graduação e de critérios objetivos de avaliação da atividade docente e em pesquisa, as principais agências nacionais de normatização e fomento têm-se deparado com questões polêmicas. Assim, para a avaliação da importância das publicações em saúde coletiva abre-se mão de índices genéricos de impacto destas publicações adotados internacionalmente, ainda que imper-feitos, por critérios internos à área. Portanto, se por um lado questiona-se o esgotamento de modelos atuais pela "pequena importância conferida às questões teóricas", por outro lado as publicações em revistas científicas, onde o escoamento desta produção seria mais apropriado, correm o risco de não serem incluídas nos índices bibliográficos reconhecidos pelos profissionais deste meio.

\section{As teses do ensaio}

Não poderia deixar de comungar com o autor do ensaio quando este chama a atenção para os desafios éticos, políticos, morais, científicos, tecnológicos, teóricos e metodológicos a serem resgatados na prática epidemiológica. Entretanto, em se aceitando que em grande parte a identificação da crise da epidemiologia surge de uma postura territorialista na definição do que seja interno ou não ao núcleo central da disciplina, a tarefa de discussão das teses do ensaio consiste, em parte, na identificação de progressos correntes em outras áreas do conhecimento, pertinentes às questões ali levantadas. Esta abordagem é implicitamente aceita pelo autor do ensaio ao reconhecer que vivemos grandes tensões epistemológicas e listar vários dos avanços recentes.

Assim, se por um lado a Epidemiologia Teórica de Miettinen (1985) exclui do domínio da epidemiologia a sua dimensão populacional em favor da individual, os avanços obtidos nesta mesma década sobre o tema da dinâmica populacional das doenças infecciosas são dignos de nota. Esta produção encontra-se solidamente registrada na obra de Anderson e May ${ }^{1}$ (1992). Muitos outros são os temas esquecidos das páginas dos livro-textos de epidemiologia mas que, entretanto, têm igualmente florescido. Por exemplo, a co-evolução entre hospedeiros e parasitas, tema central da epidemiologia evolutiva, recebeu tratamento exemplar na obra de Ewald $^{2}$ (1994). Curiosamente, a expressão Epidemiologia Evolutiva foi cunhada por Ewald, e Anderson acaba de criar o Wellcome Centre for Research on the Epidemiology of Infectious Diseases, na prestigiosa Universidade de Oxford. Portanto, am- 
bos se vêem diretamente envolvidos com o campo da epidemiologia, mas seria a recíproca verdadeira?

Entre as crises da epidemiologia moderna, MLB aponta a pequena importância conferida às questões teóricas. Esta afirmação não corresponde exatamente à minha visão. Além da produção do próprio Miettinen, citada anteriormente, que se propõe a apresentar a epidemiologia do seu ponto de vista teórico, trazendo mesmo esta expressão no título de sua obra, iremos encontrar uma vasta evidência de desenvolvimento conceitual recente da epidemiologia. A segunda versão do texto que dá origem ao objeto de considerações deste ensaio, a epidemiologia moderna, traz agora a co-autoria de Sander Greenland $^{3}$. Além das contribuições teóricas de Ken Rothman, a obra de Greenland - também em parceria com James Robins - possui um forte embasamento teórico, através da aplicação dos postulados da Inferência Causal, esta última, por sua vez, uma consequência direta de um desenvolvimento filosófico conhecido como a lógica do contra-fato. Esta abordagem teve um impacto profundo na interpretação de elementos centrais à epidemiologia como o confundimento ("confouding"), o desenho de estudo do tipo caso-controle, a direcionalidade etc. Mais recentemente, eu gostaria de chamar a atenção dos leitores para produções que permitem avanços conceituais adicionais. Halpern ${ }^{4}$ (1998) desenvolve um cenário teórico para a modelagem da incerteza, através do uso de diferentes possíveis mundos (lógica modal) que incorporam o conhecimento subjetivo, a probabilidade e o tempo. Já Pearl ${ }^{5}$ (1998) propõe a lógica do fazer, em oposição à lógica do ver, para repensar o conceito de confusão. Estas referências apenas expressam minhas preferências pessoais entre tantos outros desenvolvimentos estimulantes ao pensamento epide-miológico contemporâneo.

Louváveis, e às quais expresso minha concordância, são as propostas de desenvolvimento da epidemiologia que, ao meu ver, têm sido absorvidas pelas principais instituições brasileiras. O ambiente tem sido o objeto de projetos de pesquisa recentes sobre o impacto dos programas de despoluição da Baía de Guanabara e de Todos os Santos, sendo que as principais escolas de saúde pública, nacionais e internacionais, possuem um departamento específico dedicado à engenharia sanitária e meio ambiente. O país possui também uma área de concentração em avaliação de tecnologias em saúde, oferecida em pelo menos uma instituição, a COPPE/UFRJ, através do programa de engenharia biomédica. É sempre bom lembrar, também, que um dos primeiros textos da nossa, brasileira, epidemiologia moderna trata exatamente da desigualdade (Victora ${ }^{6}, 1988$ ).

Concluindo, eu gostoria de parabenizar o autor pelo seu provocante ensaio e compartilhar as esperanças de que a epidemiologia venha a trilhar um desenvolvimento centrado nos eixos por ele proposto. Entretanto, acredito que a epidemiologia na mordenidade vai muito bem, obrigado, e que a "crise" estaria, esta sim, nos títulos existentes em nossas bibliotecas, nos currículos de nossos cursos, e nos critérios de organização do nosso campo de atividade que, talvez, padeçam, todos, da síndrome da gafieira.

\section{Referências}

1. Anderson RM, May RM. Infectious Diseases of Humans: Dynamics and Control. Oxford: Oxford University Press; 1992.

2. Ewald PW.Evolution of Infectious Disease. Oxford:Oxford University Press; 1994.

3. Rothman KJ,Greenland S. Modern epidemiology, 2nd ed. Philadelphia: Lippincott-Raven; 1998.

4. Halpern JY. A logical approach to reasoning about uncertainty: a tutorial. In: Arrazola X, Korta K, Pelletier FJ, editors. Discourse, interaction and communication. Dordrecht: Kluwer; 1998.

5. Pearl J. Why there is no statistical test for confounding, why many think there is, and why they are almost right. Los Angeles: UCLA Computer Science Departmente/Cognitive Systems Lab; 1998.

6. Victora CG. Epidemiologia da desigualdade :um estudo longitudinal de 6.000 crianças brasileiras. São Paulo:Hucitec; 1998. 


\section{O Autor responde}

\section{The Author replies}

A decisão de escrever o ensaio em questão teve várias motivações, dentre as quais destaco: a minha experiência na comissão de epidemiologia da ABRASCO, algum tempo, inclusive, como o seu coordenador; a experiência acadêmica intensa em razão de, ao lado de outros colegas, estar participando da construção do ISC/UFBa, projeto que achamos poderá trazer elementos inovadores no que diz respeito à prática da saúde coletiva no contexto acadêmico; a condição de representante da área da Saúde Coletiva junto à CAPES tem me fornecido uma visão ampla e detalhada sobre as tendências dos vários programas de pósgraduação em saúde coletiva do país; as minhas atividades como cidadão, militante pró-SUS e, atualmente, membro do Conselho Estadual de Saúde-Bahia. Porém, antes de tudo, destaco a minha atividade como epidemiologista e pesquisador que, em associação com um grupo de colegas e alunos de diferentes formações profissionais, tem buscado contribuir na construção do conhecimento em diversos aspectos da saúde da população, os quais pensamos sejam relevantes, enfrentando as dificuldades da produção científica interdisciplinar sem apriorismos e sem buscar a reafirmação de rótulos ou adjetivos para qualquer disciplina. Neste percurso, que está longe de ser linear, é que se situa o artigo em discussão. Diferencio-me aqui dos esforços de colegas que exploram os aspectos epistemológicos da disciplina, já que o meu trabalho visou, apenas, sistematizar leituras, discussões e reflexões de um praticante. Acho que é papel de todo praticante (seja um pesquisador, seja um profissional) contextualizar, refletir, relativizar e, se possível, contribuir para transformações na sua prática.

A história do artigo merece ser sumariamente relatada, pois servirá para pavimen- tar o diálogo que manterei com meus dois ilustres comentadores. A primeira versão do texto foi concebida a partir de uma provocação para apresentá-lo em forma de palestra no V Congresso Brasileiro de Saúde Coletiva, realizado em Águas de Lindóia-SP, em agosto de 1997. A apresentação para uma platéia de mais de 100 assistentes foi recebida com comentários e críticas extremamente positivas, fato que, possivelmente, determinou a decisão da Comissão Editorial da Revista Brasileira de Epidemiologia de solicitar a sua publicação como artigo para debate na revista que então nascia. No pós-congresso, várias horas de trabalho adicional permitiram a produção de um texto revisado que, alimentando-se nas críticas, generosidade e estímulos de alguns colegas próximos, evoluiu para a versão aqui publicada. Mais recentemente, esta versão foi apresentada como palestra no IV Congresso Brasileiro de Epidemiologia, no Rio de Janeiro, tendo tido a assistência de um público ainda maior que o anterior. Ainda que a falta de tempo não tenha permitido o debate, provocou interesse, na medida em que tenho recebido várias solicitações de cópias. Tudo isto me faz acreditar que este texto pode ser uma peça útil para a reflexão e o debate intelectual sobre as ligações da epidemiologia com o campo da saúde coletiva. Com isto concordo com Moisés Goldbaum que, corretamente, cobra uma maior discussão da denominada "crise" da saúde pública, sobre a qual fiz pouca referência no texto. Para suprir esta falha remeto os leitores ao recente texto de Paim e Almeida, já referido no artigo.

A leitura dos comentários de Cláudio Struchiner provocou-me alguns sentimentos e perturbações iniciais que, paulatinamente, fizeram-me sentir parte de um saudável e estimulante debate intelectual que, sem nenhuma dúvida, evidencia 
nítidas e profundas, apesar de não irreconciliáveis, diferenças com relação a uma série de questões essenciais. Por economia de espaço buscarei ser sintético na resposta e não reafirmarei aspectos que acho já foram apresentados no corpo do artigo.

Fazer referência aos elementos de "territorialismo" contidos no meu texto é uma constatação óbvia. Aliás, a demonstração da existência dos "campos científicos" ou das "comunidades científicas" que atuam como comunidades de conhecimento, mas também como grupos de lobby, abundam nos textos de filosofia e sociologia da ciência. O que os diferencia é a agressividade com que cada grupo defende o seu "território". Acredito que nós, da saúde coletiva, somos muito mais cordatos e negociadores do que os colegas de outras áreas científicas. Nossas experiências de trânsito "entre o biológico e o social" nos fazem necessariamente parceiros ou usuários dos recursos de diversas disciplinas (portanto inter-disciplinares) e nos fazem assim sensíveis para entender as fortalezas e as mazelas de diversos campos disciplinares. Como consequência, nos fazem, também, perder a aptidão de defender com afinco qualquer que seja a disciplina. A "vaidade" não é uma categoria científica e assim, fica difícil comentá-la no contexto desta discussão. Entretanto, gostaria de explicitar uma idéia, implícita no meu texto, que espero ter oportunidade de desenvolver em detalhes em outra oportunidade. Como sanitarista e epidemiologista, no que efetivamente estou interessado e estimulado a explorar é o "conhecimento epidemiológico" em toda a sua extensão. Este conhecimento está contido nas infinitas interconexões que a epi-demiologia tem, desde o seu nascimento, com as mais diversas disciplinas (matemática, biologia, antropologia, geografia e muitas outras) e diz respeito a tudo que seja relacionado à distribuição e determinação da saúde e da doença na população humana e, em assim sendo, não tem o seu conteúdo definido por nenhuma das formas com que hoje se busca adjetivar a epidemiologia (moderna, social, molecular, evolutiva etc.).
Quanto a referência à obra de Anderson e May, também concordo que se constitui em uma importante contribuição à epidemiologia (apesar dos autores não usarem o termo no título do seu livro e serem originários de departamentos de Zoologia) que traz renovações na longa tradição do desenvolvimento de modelos matemáticos na pesquisa epidemiológica, a qual teve início nos meados do século passado com Farr e tem um dos seus pontos altos com os trabalhos do Ross, sobre a malária, no início do século(Barreto, 1990). Além das importantes contribuições para o entendimento da dinâmica de algumas doenças infecciosas, a "epidemiologia matemática" algumas vezes tem servido na definição de sólidas estratégias de controle. Apesar disto, não me incluo entre aqueles que entendem a matematização como o futuro da epidemiologia.

Em uma associação de causa-efeito, que me surpreendeu, pois não faz jus à sua prática de epidemiologista e intelectual, Struchiner evoca as idéias apresentadas no meu texto "...implicações ao nível da organização do campo...” e o associa (causalmente!) à decisão da comissão de avaliação da pós-graduação em Saúde Coletiva, a qual coordenei, com relação à categorização da importância das revistas científicas. A decisão sobre o sistema de classificação de periódicos científicos da área foi tomada por uma comissão de oito especialistas das diversas sub-áreas da Saúde Coletiva (que o usou com tal grau de parcimônia que ninguém poderá sentir-se prejudicado pelo seu uso) e por duas vezes foi discutida no forum de coordenadores de pós-graduação em saúde coletiva da ABRASCO, o qual, se não o ratificou, também não fez críticas que a desqualificassem. Quanto à proposta de Struchiner de utilizar “...índices genéricos de impacto destas publicações, adotados internacionalmente...", devo dizer que estes índices não são tão genéricos assim, na medida em que não refletem a produção científica dos países do terceiro-mundo, nem de todas as áreas científicas. Estes encontram seus maiores adeptos no campo das ciências hard, sendo de uso limitado 
em campos como as ciências sociais e desprezados nas ciências sociais brasileiras. A sua aplicação na saúde coletiva, enquanto pudesse servir para medir a produção de algumas das suas sub-áreas (principalmente a epidemiologia) seria, sem nenhuma dúvida, danosa para outras, ferindo frontalmente a "multi-disciplinaridade", tão cara à área e de que Struchiner apresenta-se como defensor.

Por fim gostaria de dizer que, apesar de todo a minha apreciação como ouvin- te da gafieira, minhas tradições culturais e minha prática de dançador vem do forró e chegam ao axé, em suas diversas variações. Quem as conhece sabe que estas são praticadas em terreiros e praças, portanto, como a gafieira, constituem-se em espaços democráticos de expressão corporal porém, diferente da Síndrome da Gafieira descrita por Struchiner(1998), geram espaços de movimentação extremamente dinâmicos, onde o entra-e-sai faz parte da folia. 